Research Article

\title{
Investigation on Influences of Two Discrete Methods on Galloping Characteristics of Iced Quad Bundle Conductors
}

\author{
Xiaohui Liu $\mathbb{D},{ }^{1}$ Guangyun Min $\mathbb{D D}^{2},{ }^{2}$ Chuan Wu $\mathbb{D}^{3},{ }^{3}$ and Mengqi Cai $\mathbb{D}^{4}$ \\ ${ }^{1}$ State Key Laboratory of Mountain Bridge and Tunnel Engineering, Chongqing Jiaotong University, Chongqing 400074, China \\ ${ }^{2}$ School of Civil Engineering, Chongqing Jiaotong University, Chongqing 400074, China \\ ${ }^{3}$ State Grid Henan Electric Power Research Institute, Zhengzhou 450052, China \\ ${ }^{4}$ School of Architecture and Civil Engineering, Chengdu University, Chengdu 610106, China \\ Correspondence should be addressed to Xiaohui Liu; cqdxlxh@126.com
}

Received 19 May 2020; Revised 10 October 2020; Accepted 17 October 2020; Published 5 November 2020

Academic Editor: Chiara Bedon

Copyright (๑) 2020 Xiaohui Liu et al. This is an open access article distributed under the Creative Commons Attribution License, which permits unrestricted use, distribution, and reproduction in any medium, provided the original work is properly cited.

\begin{abstract}
The partial differential galloping equation of iced quad conductors can be transformed into an ordinary differential galloping equation by two discrete methods: one is a direct discrete method and the other is an indirect discrete method. The two discrete methods are reasonable and effective and have their own advantages and disadvantages, but whether the two different discrete methods would cause the differences in galloping characteristics of the iced quad conductor has not been studied. Based on this concept, this paper studies this problem systematically. Firstly, based on the variational principle for Hamiltonian, the partial differential galloping equation with 3DOFs of the iced quad bundle conductor is derived and then two discrete methods are used to transform the partial differential galloping equation into an ordinary differential galloping equation. One is to use a direct method to transform partial differential galloping equation into an ordinary differential galloping equation, while the other is to use an indirect method to transform partial differential galloping equation into an ordinary differential galloping equation. Secondly, based on the wind tunnel test, the three-component aerodynamic coefficients of each subconductor of the iced quad conductor are obtained, and the equivalent aerodynamic coefficients at the central axis of the quad bundle conductor are obtained by using a reasonable method. Then, the aerodynamic coefficients are fitted by Taylor rules and the aerodynamic coefficients of wind angle of attack which is $55^{\circ}$ are used in the analysis of galloping characteristics of the iced quad conductor. Finally, based on the numerical method, the displacement response of the two discrete methods is obtained. By comparing the differences of the displacement response obtained by the two discrete methods, it is found that the two discrete methods have certain influences on the phase, frequency, and amplitude of the iced quad bundle conductor. By comparing the calculation process of these two discrete methods, it can be obtained that the calculation process of the direct discrete method is more complex and the calculation process of the indirect discrete method is simpler. By comparing the calculation results of these two discrete methods, the amplitude obtained by the indirect discrete method is bigger than that obtained by the direct discrete method, especially the amplitude in the torsional direction. The research conclusion of this paper can offer some guidance to civil and electric engineering.
\end{abstract}

\section{Introduction}

With the rapid development of power grid, the galloping characteristics of iced transmission lines have attracted the attention of most scholars [1-5]. In fact, the span length of transmission lines is far larger than its diameter, which belongs to the flexible cable structure. For cable structure, Irvine firstly studied the statics and linear and nonlinear dynamics of the suspension cable structure and proposed important Irvine parameters [6]. Perkins divided the external excitation of elastic suspension cable into two types, parametric excitation and periodic excitation, and studied the interaction between mode shapes and mode shapes of elastic suspension cable [7]. Rega firstly systematically expounded the mechanical modeling, response, and nonlinear phenomena of the suspension cable from the theoretical analysis, then verified the correctness of the theoretical analysis from the experiment, and found lots of 
valuable guidance and suggestions for civil and electric engineering [8]. Some scholars also have made many contributions to the study of suspension structure. Lilien and Havard established the finite element model of conductor with 6-DOF joints based on the space curved beam theory, then used the Newton-Raphson method to solve the static nonlinear problem, and found some very meaningful conclusions [9]. Based on the existing research, Yan et al. considered the influences of bending stiffness on the suspension cable and modified the error of bending stiffness not considered in the existing literature [10]. According to the variational principle for Hamiltonian, Xiao et al. deduced the nonlinear dynamic equation with 3DOFs considering bending stiffness of suspension cable, then analyzed the possible internal resonance modes of the cable by the multiscale method, and studied the influences of bending stiffness on internal resonance by the numerical method [11].

Although the existing papers are based on the cable structure to analyze the vibration characteristics of iced transmission lines, the galloping of iced transmission lines is different from the vibration of cable. Because the galloping characteristics of transmission lines are related to ice type, ice thickness, and other factors, the galloping of transmission lines is essentially a fluid-structure coupling. vibration. Because the galloping of iced transmission lines is affected by aerodynamic loads, the top priority of studying the galloping characteristics is to obtain the three-dimensional aerodynamic coefficients of transmission lines. Zhao et al. analyzed the actual galloping data of a single conductor, two-bundle conductor, three-bundle conductor, and quad bundle conductor and then obtained some valuable results, which can provide some references for the study of the galloping characteristics of conductor [12]. Kimura et al. made the static wind tunnel test and dynamic wind tunnel test on the crescent iced conductor and then analyzed the differences between static aerodynamic characteristics and dynamic aerodynamic characteristics [13]. Lou et al. investigated the influences of iced thickness, initial iced accretion angle, and subconductor on the aerodynamic properties [14], and Cai et al. measured the aerodynamic coefficients of the iced 8bundle conductor under different turbulence intensities flow by the wind tunnel experiment [15].

In order to study the galloping characteristics of the iced quad conductor, the partial differential galloping equation of iced quad conductor is firstly required; then the partial differential galloping equation should be transformed into an ordinary differential galloping equation by the reasonable method. While according to existing literature, it can be found that some scholars are used to choose the direct discrete method to transform the partial differential galloping equation into ordinary differential galloping equation, while others are used to select the indirect discrete method to transform partial differential galloping equation into ordinary differential galloping equation. These two discrete methods both are correct and effective, but whether these two discrete methods would affect the galloping characteristics of the iced quad bundle conductor has not been studied by anyone. Based on this concept, this paper systematically studies the influences of the two different discrete methods on galloping characteristics of the iced quad bundle conductor. In this paper, the partial differential galloping equation of iced quad conductor with 3DOFs is established firstly, then two different methods are used to transform the partial differential galloping equation into an ordinary differential galloping equation. Then, through the wind tunnel test, the three-component aerodynamic coefficients of the quad bundle conductor are measured, and the equivalent aerodynamic coefficients at the central axis of the quad bundle conductor are obtained by a reasonable method. Finally, the galloping characteristics of the iced quad conductor are studied, and the influences of two different discrete methods on the displacement response of the iced quad conductor are also investigated.

\section{Galloping Equation of the Iced Conductor}

2.1. Mathematical Model and Galloping Equation. The mathematical model of transmission lines is established as shown in Figure 1. The two ends of the conductor are constrained by fixed supports. $\Gamma_{1}$ is the equilibrium configuration under the action of gravity and $\Gamma_{2}$ is the dynamic configuration under the action of gravity and other external loads.

In order to obtain the galloping equation of the conductor, the Cartesian coordinate system has been established and the left support of the conductor has been taken as the origin of the Cartesian coordinate system, which can be seen in Figure 1.

Because of the influences of iced, the cross-sectional area of the conductor would become noncircular, so its center of mass is not at the center of the circle. The variational principle for Hamiltonian belongs to the energy method, which is essentially the conservation of energy in the system. Although the conductor would rotate eccentrically due to the influences of iced, the variational principle for Hamiltonian would be also suitable for the derivation of the galloping equation of the conductor. Since it can be obtained from the variational principle for Hamiltonian,

$$
\int \delta k^{v}-\int \delta \prod+\int \delta w^{\prime}=0
$$

where $\delta k^{v}$ is the kinetic energy of the iced conductor, $\delta \prod$ is the potential energy of the iced conductor, and $\delta w^{\prime}$ is the virtual work associated with gravity, external, and damping forces.

Kinetic energy, potential energy, and virtual work of the conductor are, respectively, as follows:

$$
\int_{0}^{l} k^{v} \mathrm{~d} s=\int_{0}^{l} \frac{1}{2} m \dot{u}_{i}^{2} \mathrm{~d} s+\frac{1}{2} \int_{0}^{l} J \dot{\theta}^{2} \mathrm{~d} s+\int_{0}^{l} s_{z} \dot{u}_{3} \dot{\theta} \mathrm{d} s-\int_{0}^{l} s_{y} \dot{u_{2}} \dot{\theta} \mathrm{d} s,
$$

$$
\begin{aligned}
\int_{0}^{l} \prod \mathrm{d} s= & \int_{0}^{l}\left(T \varepsilon+\frac{1}{2} \mathrm{EA} \varepsilon^{2}\right) \mathrm{d} s \\
& +\frac{1}{2}\left[\int_{0}^{l} \mathrm{EI}\left(\frac{\partial^{2} u_{i}}{\partial s^{2}}\right)^{2} \mathrm{~d} s+\int_{0}^{l} \mathrm{GI}_{P} \varepsilon_{\theta}^{2} \mathrm{~d} s\right]
\end{aligned}
$$




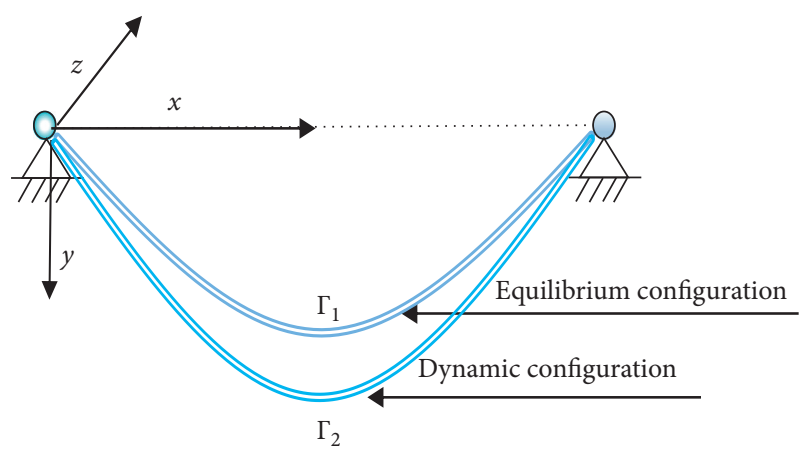

Figure 1: The mathematical model of the conductor.

$$
\int_{0}^{l} \delta w^{\prime} \mathrm{d} s=\left(\sum_{i=1}^{3} p_{i}-c_{i} \dot{u}_{i}\right)+\left(p_{\theta}-c_{\theta} \dot{\theta}\right)
$$

where $S_{Z}$ and $S_{y}$ are static moments, EI is bending stiffness, EA is tensile stiffness, $\mathrm{GI}_{P}$ is torsional stiffness, $\varepsilon$ is tensile strain, $J$ is moment of inertia, $\theta$ is torsional angle, $u_{i}$ is dynamic displacement, $\varepsilon_{\theta}$ is torsional strain, $p_{i}$ and $p_{\theta}$ are external aerodynamic forces, $c_{i}$ and $c_{\theta}$ are damping coefficients, $T$ is static tension, and $l$ is span length.
Substituting equations (2a)-(2c) into equation (1), can obtain that

$$
\begin{aligned}
\frac{\partial}{\partial s}\left\{H\left(\frac{\mathrm{d} x_{i}}{\mathrm{~d} s}+\frac{\partial u_{i}}{\partial s}\right)+\mathrm{EA} \Theta\right\}= & \left(j \ddot{\theta}+S_{z} \ddot{u}_{3}-S_{y} \ddot{u}_{2}\right) \delta_{i \theta} \\
& +\left(S_{z} \delta_{i 3}-S_{y} \delta_{i 2}\right) \ddot{\theta}+\mathrm{EI} \frac{\partial^{4} u_{i}}{\partial s} \\
& -\mathrm{GI}_{p} \frac{\partial^{2} \theta}{\partial x_{1}} \delta_{i \theta}+m u_{i},
\end{aligned}
$$

where

$$
\Theta=\left[\frac{\mathrm{d} x_{i}}{\mathrm{~d} s} \frac{\partial u_{i}}{\partial s}+\frac{1}{2}\left(\frac{\partial u_{i}}{\partial s}\right)^{2}\right]\left(\frac{\mathrm{d} x_{i}}{\mathrm{~d} s}+\frac{\partial u_{i}}{\partial s}\right) .
$$

Only considering the vertical $\left(u_{2}\right)$, transverse $\left(u_{3}\right)$, and torsional $(\theta)$ movement of the conductor and ignoring the horizontal $\left(u_{1}\right)$ movement of the conductor and then substituting equation (4) into equation (3), the partial differential galloping equation of the conductor in vertical $\left(u_{2}\right)$, transverse $\left(u_{3}\right)$, and torsional direction $(\theta)$ can be obtained as follows:

$$
\begin{gathered}
\frac{\partial}{\partial x}\left\{\mathrm{EA}\left[\frac{\mathrm{d} y}{\mathrm{~d} x} \frac{\partial u_{2}}{\partial x}+\frac{1}{2}\left[\left(\frac{\partial u_{2}}{\partial x}\right)^{2}+\left(\frac{\partial u_{3}}{\partial x}\right)^{2}\right]\right]\left(\frac{\mathrm{d} y}{\mathrm{~d} x}+\frac{\partial u_{2}}{\partial x}\right)+H \frac{\partial u_{2}}{\partial x}\right\}=m \ddot{u}_{2}-S_{y} \ddot{\theta}+\mathrm{EI} \frac{\partial^{4} u_{2}}{\partial x^{4}}+f_{2} \dot{u}_{2}-p_{2}, \\
\frac{\partial}{\partial x}\left\{\mathrm{EA}\left[\frac{\mathrm{d} y}{\mathrm{~d} x} \frac{\partial u_{2}}{\partial x}+\frac{1}{2}\left[\left(\frac{\partial u_{2}}{\partial x}\right)^{2}+\left(\frac{\partial u_{3}}{\partial x}\right)^{2}\right]\right]\left(\frac{\partial u_{3}}{\partial x}\right)+H \frac{\partial u_{3}}{\partial x}\right\}=m \ddot{u}_{3}+S_{z} \ddot{\theta}+\mathrm{EI} \frac{\partial^{4} u_{3}}{\partial x^{4}}+f_{3} \dot{u}_{3}-p_{3}, \\
\left(J \ddot{\theta}+S_{z} \ddot{u}_{3}-S_{y} \ddot{u}_{2}\right)-\mathrm{GI}_{p} \frac{\partial^{2} \theta}{\partial x}+f_{\theta} \dot{\theta}-p_{\theta}=0 .
\end{gathered}
$$

$$
\theta(x, t)=\psi_{\theta}(x) q_{\theta}(t)
$$

2.2. Direct Discrete Method. The experts represented by Lou et al. $[16,17]$ generally transformed the partial differential galloping equation into an ordinary differential galloping equation by direct discrete method; that is, equation (4) is directly substituted into equation (3).

The detailed steps of the direct discrete method are given below. The dynamic displacements can be expressed as

$$
\begin{aligned}
& u_{2}(x, t)=\psi_{2}(x) q_{2}(t), \\
& u_{3}(x, t)=\psi_{3}(x) q_{3}(t),
\end{aligned}
$$

where $\psi_{2}, \psi_{3}$, and $\psi_{\theta}$ are mode shapes and $q_{2}, q_{3}$, and $q_{\theta}$ are vibration functions.

Substituting equations (6a)-(6c) into equations (5a)-(5c), then it can be obtained that

$$
\begin{gathered}
\frac{\partial}{\partial x}\left\{H \psi_{2}^{\prime} q_{2}+\operatorname{EA} \ell\left(y^{\prime}+\psi_{2}^{\prime} q_{2}\right)\right\}=m \psi_{2} \ddot{q}_{2}-S_{y} \psi_{\theta} \ddot{q}_{\theta}+\mathrm{EI}_{\psi}^{\prime \prime \prime \prime} q_{2}+f_{2} \psi_{2} \dot{q}_{2}-p_{2}, \\
\frac{\partial}{\partial x}\left\{H \psi_{3}^{\prime} q_{3}+\operatorname{EA} \ell\left(\psi_{3}^{\prime} q_{3}\right)\right\}=m \psi_{3} \ddot{q}_{3}+S_{z} \psi_{\theta} \ddot{q}_{\theta}+\mathrm{EI} \psi_{3}^{\prime \prime \prime \prime} q_{3}+f_{3} \psi_{3} \dot{q}_{3}-p_{3}, \\
\left(J \psi_{\theta} \ddot{q}_{\theta}-S_{z} \psi_{3} \ddot{q}_{3}+S_{y} \psi_{2} \ddot{q}_{2}\right)=\mathrm{GI}_{p} \psi_{\theta}^{\prime} q_{\theta}-f_{\theta} \psi_{\theta} \dot{q}_{\theta}+p_{\theta},
\end{gathered}
$$


where

$$
\ell=y^{\prime} \psi_{2}^{\prime} q_{2}+\frac{1}{2}\left(\psi_{2}^{\prime 2} q_{2}^{2}+\psi_{3}^{\prime 3} q_{3}^{2}\right)
$$

Using the Galerkin method for equation (7a), then it can be obtained that

$$
b_{1} \ddot{q}_{2}+b_{2} \dot{q}_{2}+b_{4} q_{2}+b_{5} q_{2}^{2}+b_{6} q_{3}^{2}+b_{8} q_{2}^{3}+b_{9} q_{2} q_{3}^{2}+b_{10} \ddot{q}_{\theta}=p p_{2} .
$$

Using the Galerkin method for equation (7b), then it can be obtained that

$$
c_{1} \ddot{q}_{3}+c_{2} \dot{q}_{3}+c_{3} q_{3}+c_{5} q_{2} q_{3}+c_{6} q_{2}^{2} q_{3}+c_{7} q_{3}^{3}+c_{8} \ddot{q}_{\theta}=p p_{3} .
$$

Using the Galerkin method for equation (7c), then it can be obtained that

$$
d_{1} \ddot{q}_{\theta}+d_{2} \dot{q}_{\theta}+d_{3} \ddot{q}_{3}+d_{4} \ddot{q}_{2}+d_{5} q_{\theta}=p p_{4} .
$$

Equations (9a)-(9c) are the three-degree-of-freedom coupling ordinary differential galloping equation of iced conductor obtained by the direct discrete method, and the expression of the coefficients involved in equations (9a)-(9c) is shown in the appendix.

2.3. Indirect Discrete Method. Some experts [18, 19] thought that the axial galloping of the iced conductor is very weak, so the influences of its axial inertia force can be ignored. Based on this concept, equation (4) can be averaged along the span length; that is,

$$
\Theta^{m}=\frac{1}{l} \int_{0}^{l}\left[\frac{\mathrm{d} x_{i}}{\mathrm{~d} s} \frac{\partial u_{i}}{\partial s}+\frac{1}{2}\left(\frac{\partial u_{i}}{\partial s}\right)^{2}\right]\left(\frac{\mathrm{d} x_{i}}{\mathrm{~d} s}+\frac{\partial u_{i}}{\partial s}\right) \mathrm{d} x .
$$

Substituting equation (10) into equations (5a)-(5c), then it can be obtained that

$$
\begin{gathered}
\frac{\partial}{\partial x}\left\{\frac{\mathrm{EA}}{l} \int_{0}^{l} \frac{\mathrm{d} y}{\mathrm{~d} x} \frac{\partial u_{2}}{\partial x}+\frac{1}{2}\left[\left(\frac{\partial u_{2}}{\partial x}\right)^{2}+\left(\frac{\partial u_{3}}{\partial x}\right)^{2}\right] \mathrm{d} x\left(\frac{\mathrm{d} y}{\mathrm{~d} x}+\frac{\partial u_{2}}{\partial x}\right)+H \frac{\partial u_{2}}{\partial x}\right\}=m \ddot{u}_{2}-S_{y} \ddot{\theta}+\mathrm{EI} \frac{\partial^{4} u_{2}}{\partial x^{4}}+f_{2} \dot{u}_{2}-p_{2}, \\
\frac{\partial}{\partial x}\left\{\frac{\mathrm{EA}}{l} \int_{0}^{l} \frac{\mathrm{d} y}{\mathrm{~d} x} \frac{\partial u_{2}}{\partial x}+\frac{1}{2}\left[\left(\frac{\partial u_{2}}{\partial x}\right)^{2}+\left(\frac{\partial u_{3}}{\partial x}\right)^{2}\right] \mathrm{d} x\left(\frac{\partial u_{3}}{\partial x}\right)+H \frac{\partial u_{3}}{\partial x}\right\}=m \ddot{u}_{3}+S_{z} \ddot{\theta}+\mathrm{EI} \frac{\partial^{4} u_{3}}{\partial x^{4}}+f_{3} \dot{u}_{3}-p_{3}, \\
\left(J \ddot{\theta}+S_{z} \ddot{u}_{3}-S_{y} \ddot{u}_{2}\right)-\mathrm{GI}_{p} \frac{\partial^{2} \theta}{\partial x}+f_{\theta} \dot{\theta}-p_{\theta}=0 .
\end{gathered}
$$

Substituting equations (6a)-(6c) into equation (11a) and using the Galerkin method, then it can be obtained that

$b_{1}^{\prime} \ddot{q}_{2}+b_{2}^{\prime} \dot{q}_{2}+b_{4}^{\prime} q_{2}+b_{5}^{\prime} q_{2}^{2}+b_{6}^{\prime} q_{3}^{2}+b_{8}^{\prime} q_{2}^{3}+b_{9}^{\prime} q_{2} q_{3}^{2}+b_{10}^{\prime} \ddot{q}_{\theta}=p p_{2}^{\prime}$.

Substituting equations (6a)-(6c) into equation (11b) and using the Galerkin method, then it can be obtained that

$$
c_{1}^{\prime} \ddot{q}_{3}+c_{2}^{\prime} \dot{q}_{3}+c_{3}^{\prime} q_{3}+c_{5}^{\prime} q_{2} q_{3}+c_{6}^{\prime} q_{2}^{2} q_{3}+c_{7}^{\prime} q_{3}^{3}+c_{8}^{\prime} \ddot{q}_{\theta}=p p_{3}^{\prime} .
$$

Substituting equations (6a)-(6c) into equation (11c) and using the Galerkin method, then it can be obtained that

$$
d_{1}^{\prime} \ddot{q}_{\theta}+d_{2}^{\prime} \dot{q}_{\theta}+d_{3}^{\prime} \ddot{q}_{3}+d_{4}^{\prime} \ddot{q}_{2}+d_{5}^{\prime} q_{\theta}=p p_{4}^{\prime} .
$$

Equations (12a)-(12c) are the three-degree-of-freedom coupling ordinary differential galloping equation of the iced conductor obtained by the indirect discrete method.

2.4. Aerodynamic Loads on the Iced Conductor. The mathematical model of aerodynamic load on the iced conductor is established as shown in Figure 2. The iced model is crescent, $F_{\mathrm{L}}$ is aerodynamic lift, $F_{\mathrm{D}}$ is aerodynamic drag, $U$ is true wind speed, $U \mathrm{r}$ is relative wind speed, and $D$ is the diameter of the conductor. $p_{2}$ is aerodynamic load in the vertical direction, $p_{3}$ is aerodynamic load in the transverse direction, $p_{\theta}$ is the aerodynamic load in the torsional direction; then,

$$
\begin{aligned}
& p_{2}=F_{\mathrm{L}} \cos \left(\alpha_{t}\right)-F_{\mathrm{D}} \sin \left(\alpha_{t}\right)=0.5 \rho U^{2} D C_{y}(\alpha), \\
& p_{3}=F_{\mathrm{L}} \sin \left(\alpha_{t}\right)+F_{\mathrm{D}} \cos \left(\alpha_{t}\right)=0.5 \rho U^{2} D C_{z}(\alpha), \\
& p_{\theta}=0.5 \rho U^{2} D^{2} C_{M}(\alpha)
\end{aligned}
$$

where $C_{y}(\alpha), C_{z}(\alpha)$, and $C_{M}(\alpha)$ are aerodynamic coefficients, $\alpha$ is instantaneous wind angle of attack, and $\rho$ is air density. The aerodynamic coefficients can be fitted by a cubic curve; that is,

$$
\begin{gathered}
C_{y}(\alpha)=\alpha_{1} \alpha+\alpha_{2} \alpha^{2}+\alpha_{3} \alpha^{3}, \\
C_{z}(\alpha)=\beta_{1} \alpha+\beta_{2} \alpha^{2}+\beta_{3} \alpha^{3}, \\
C_{M}(\alpha)=\gamma_{1} \alpha+\gamma_{2} \alpha^{2}+\gamma_{3} \alpha^{3},
\end{gathered}
$$

where $\alpha_{i}, \beta_{i}$, and $\gamma_{i}$ are the three-component coefficients determined by wind tunnel test, which are related to the initial wind angle of attack, torsional angle, and relative wind speed. 


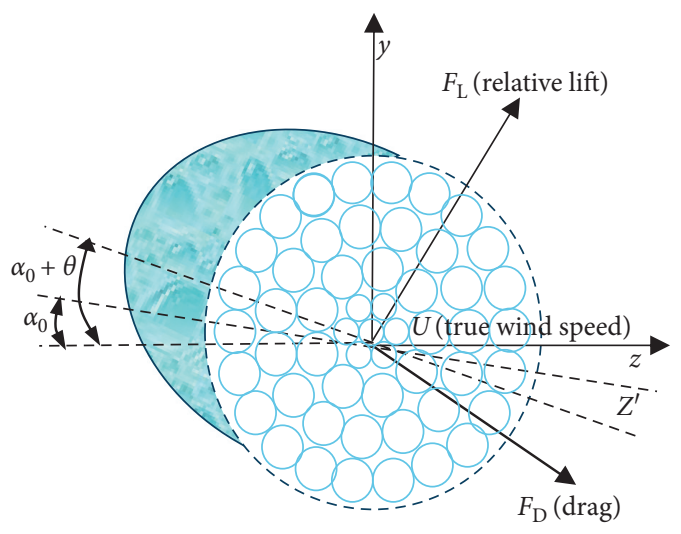

(a)

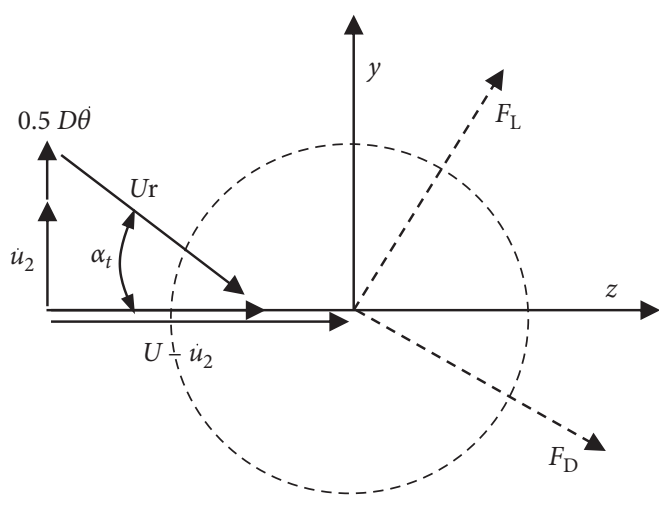

(b)

FiguRE 2: Cross-sectional model of the iced conductor and relative flow. (a) Cross-sectional model of the iced conductor. (b) Relative flow in the quasi-steady assumption.

According to equations (13a)-(13c) and equations (14a)-(14c), then using the Galerkin method, it can be obtained that

$$
\begin{aligned}
& p p_{2}=p p_{2}^{\prime}(t)=\int_{0}^{l} \frac{1}{2} \rho U^{2} D\left(\left(-\frac{\alpha_{1}}{U}\right) \psi_{2}(x) \dot{q}_{2}(t)+\left(\frac{\alpha_{2}}{U^{2}}\right)\left[\psi_{2}(x) \dot{q}_{2}(t)\right]^{2}-\left(\frac{\alpha_{3}}{U^{3}}\right)\left[\psi_{2}(x) \dot{q}_{2}(t)\right]^{3}\right) \psi_{2}(x) \mathrm{d} x, \\
& p p_{3}=p p_{3}^{\prime}(t)=\int_{0}^{l} \frac{1}{2} \rho U^{2} D\left(\left(-\frac{\beta_{1}}{U}\right) \psi_{2}(x) \dot{q}_{2}(t)+\left(\frac{\beta_{2}}{U^{2}}\right)\left[\psi_{2}(x) \dot{q}_{2}(t)\right]^{2}-\left(\frac{\beta_{3}}{U^{3}}\right)\left[\psi_{2}(x) \dot{q}_{2}(t)\right]^{3}\right) \psi_{3}(x) \mathrm{d} x, \\
& p p_{4}=p p_{4}^{\prime}(t)=\int_{0}^{l} \frac{1}{2} \rho U^{2} D^{2}\left(\left(-\frac{\gamma_{1}}{U}\right) \psi_{2}(x) \dot{q}_{2}(t)+\left(\frac{\gamma_{2}}{U^{2}}\right)\left[\psi_{2}(x) \dot{q}_{2}(t)\right]^{2}-\left(\frac{\gamma_{3}}{U^{3}}\right)\left[\psi_{2}(x) \dot{q}_{2}(t)\right]^{3}\right) \psi_{3}(x) \mathrm{d} x .
\end{aligned}
$$

By substituting equations (15a)-(15c) into equations (9a)-(9c), the ordinary differential equation with considering the influences of aerodynamic loads on the iced conductor under direct discrete method can be obtained as follows:

$$
\left\{\begin{array}{l}
b_{1} \ddot{q}_{2}+\left(b_{2}+b^{*}\right) \dot{q}_{2}+b_{4} q_{2}+b_{5} q_{2}^{2}+b_{6} q_{3}^{2}+b_{8} q_{2}^{3}+b_{9} q_{2} q_{3}^{2}+b_{10} \ddot{q}_{\theta}+b_{11}^{*} \dot{q}_{2}^{2}+b_{12}^{*} \dot{q}_{2}^{3}=0 \\
c_{1} \ddot{q}_{3}+c_{2} \dot{q}_{3}+c_{3} q_{3}+c_{5} q_{2} q_{3}+c_{6} q_{2}^{2} q_{3}+c_{7} q_{3}^{3}+c_{8} \ddot{q}_{\theta}+c_{9}^{*} \dot{q}_{2}+c_{10}^{*} \dot{q}_{2}^{2}+c_{11}^{*} \dot{q}_{2}^{3}=0 \\
d_{1} \ddot{q}_{\theta}+d_{2} \dot{q}_{\theta}+d_{3} \ddot{q}_{3}+d_{4} \ddot{q}_{2}+d_{5} q_{\theta}+d_{6}^{*} \dot{q}_{2}+d_{7}^{*} \dot{q}_{2}^{2}+d_{8}^{*} \dot{q}_{2}^{3}=0
\end{array}\right.
$$

where the expression of the coefficients involved in equation (16) is shown in the appendix.
By substituting equations (15a)-(15c) into equations (12a)-(12c), the ordinary differential equation with 


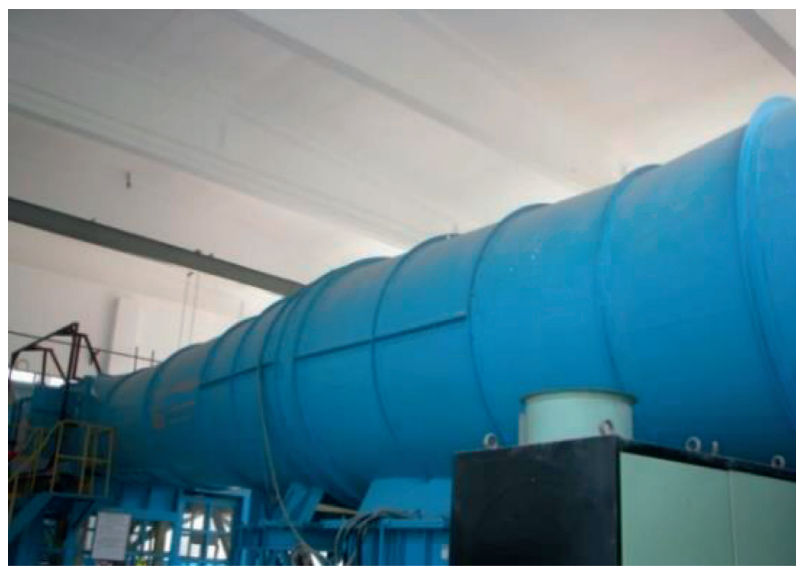

FIGURE 3: Wind tunnel with low wind speed $(1.4 \mathrm{~m} \times 1.4 \mathrm{~m})$.

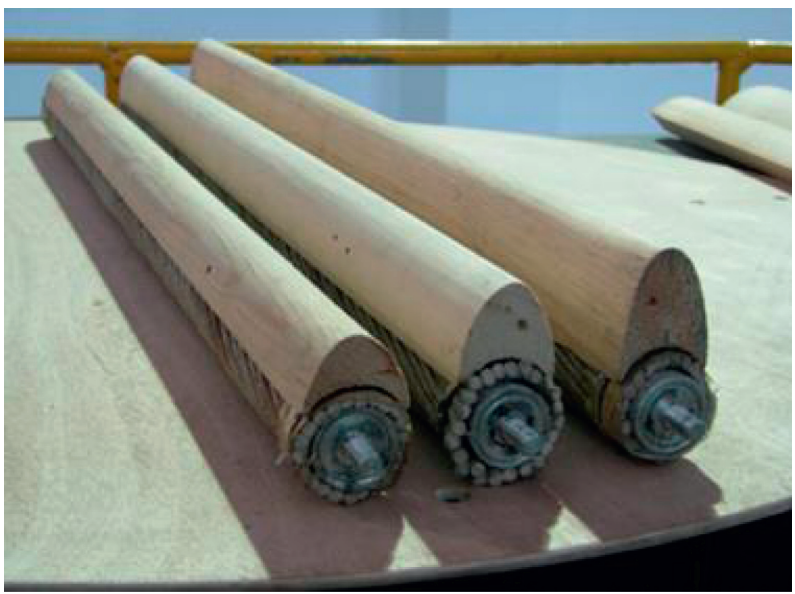

Figure 4: Iced model.

considering the influences of aerodynamic loads on the iced conductor under indirect discrete method can be obtained as follows:

$$
\left\{\begin{array}{l}
b_{1}^{\prime} \ddot{q}_{2}+\left(b_{2}^{\prime}+b^{*}\right) \dot{q}_{2}+b_{4}^{\prime} q_{2}+b_{5}^{\prime} q_{2}^{2}+b_{6}^{\prime} q_{3}^{2}+b_{8}^{\prime} q_{2}^{3}+b_{9}^{\prime} q_{2} q_{3}^{2}+b_{10}^{\prime} \ddot{q}_{\theta}+b_{11}^{*} \dot{q}_{2}^{2}+b_{12}^{*} \dot{q}_{2}^{3}=0 \\
c_{1}^{\prime} \ddot{q}_{3}+c_{2}^{\prime} \dot{q}_{3}+c_{3}^{\prime} q_{3}+c_{5}^{\prime} q_{2} q_{3}+c_{6}^{\prime} q_{2}^{2} q_{3}+c_{7}^{\prime} q_{3}^{3}+c_{8}^{\prime} \ddot{q}_{\theta}+c_{9}^{*} \dot{q}_{2}+c_{10}^{*} \dot{q}_{2}^{2}+c_{11}^{*} \dot{q}_{2}^{3}=0, \\
d_{1}^{\prime} \ddot{q}_{\theta}+d_{2}^{\prime} \dot{q}_{\theta}+d_{3}^{\prime} \ddot{q}_{3}+d_{4}^{\prime} \ddot{q}_{2}+d_{5}^{\prime} q_{\theta}+d_{6}^{*} \dot{q}_{2}+d_{7}^{*} \dot{q}_{2}^{2}+d_{8}^{*} \dot{q}_{2}^{3}=0,
\end{array}\right.
$$

where the expression of the coefficients involved in equation (17) is shown in the appendix.

\section{Wind Tunnel Tests}

In order to obtain the three-component aerodynamic coefficients of the crescent iced quad bundle conductor, the wind tunnel test was carried out in China Aerodynamics Research and Development center. The quasi-static method is used to test the aerodynamic coefficients of a cross-sectional model of the iced conductor. The picture of $1.4 \mathrm{~m} \times 1.4 \mathrm{~m}$ wind tunnel with low wind speed is shown in
Figure 3, the picture of the iced model is shown in Figure 4, and the picture of the force-measuring model is shown in Figure 5 .

After measuring the aerodynamic loads, the top motor of force-measuring model would drive force-measuring model to rotate $5^{\circ}$; then, the aerodynamic load is measured again and the range of measurement is $0^{\circ} \sim 180^{\circ}$. The aerodynamic coefficients of the iced quad bundle conductor measured by the wind tunnel test include aerodynamic drag, lift, and moment coefficients; then, the dimensionless aerodynamic parameters are defined as follows: 


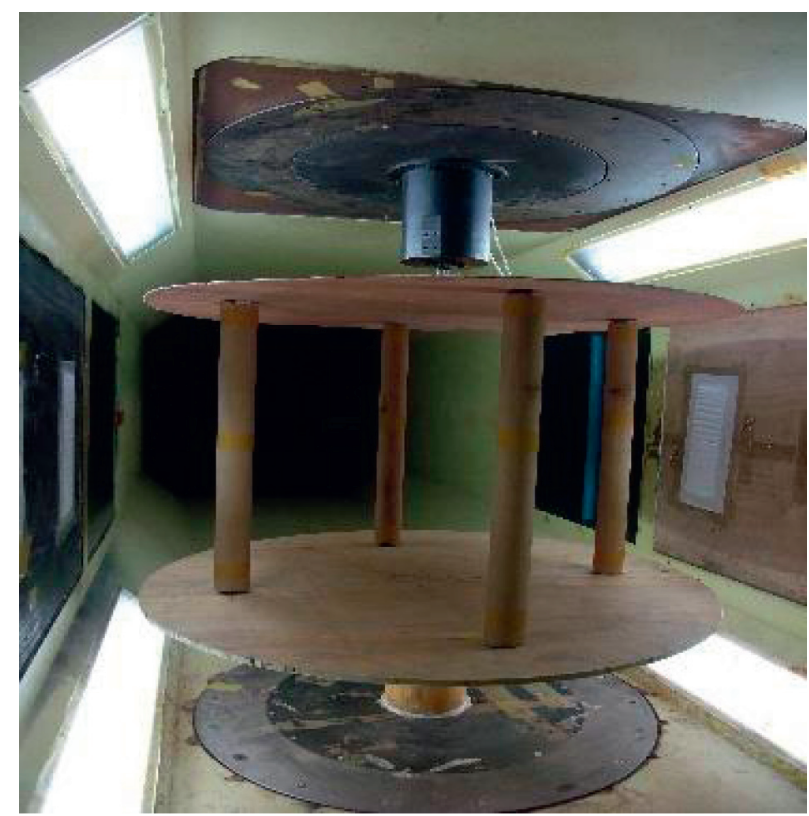

Figure 5: Force-measuring model.

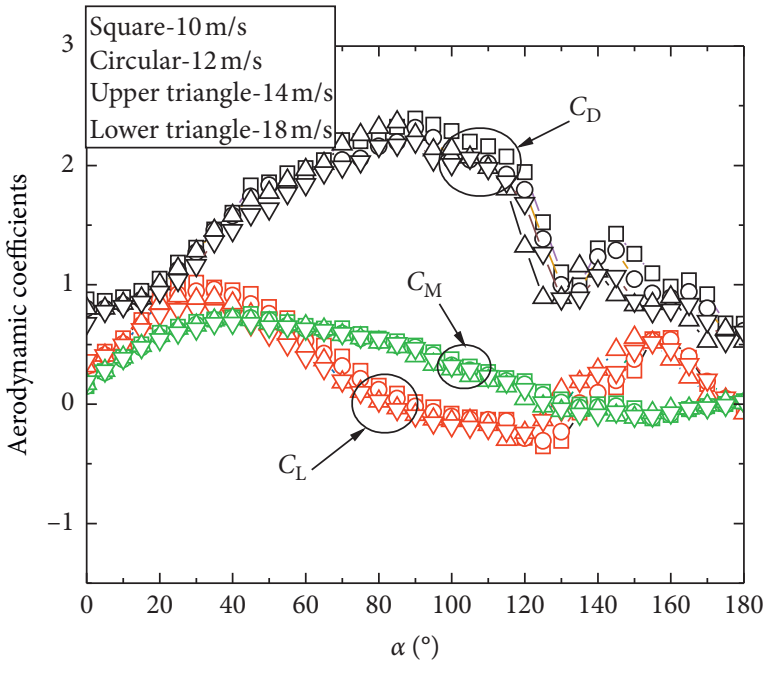

(a)

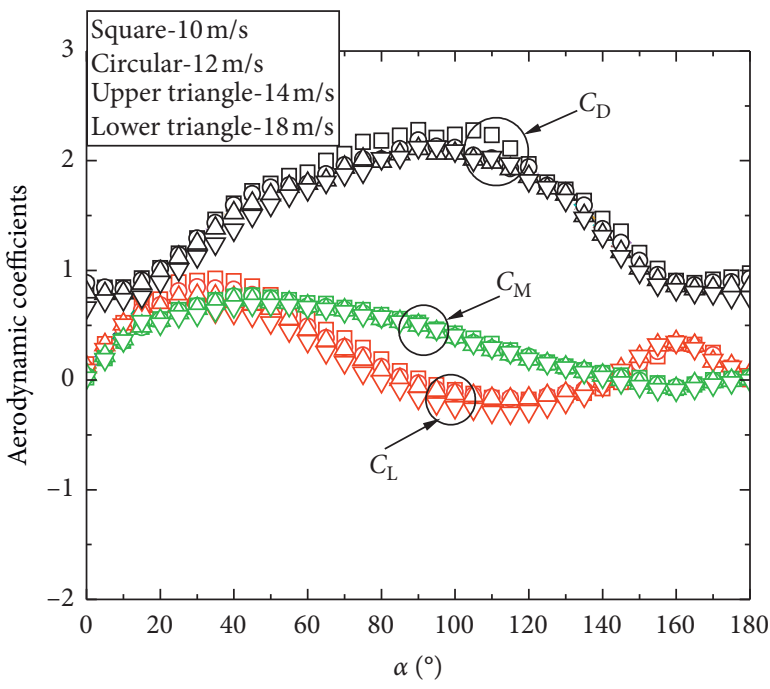

(b)

Figure 6: Continued. 


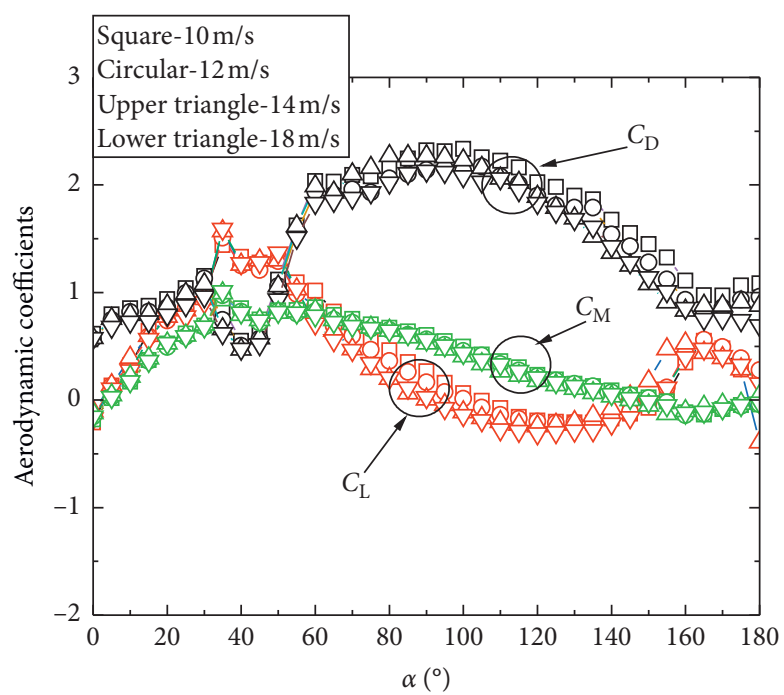

(c)

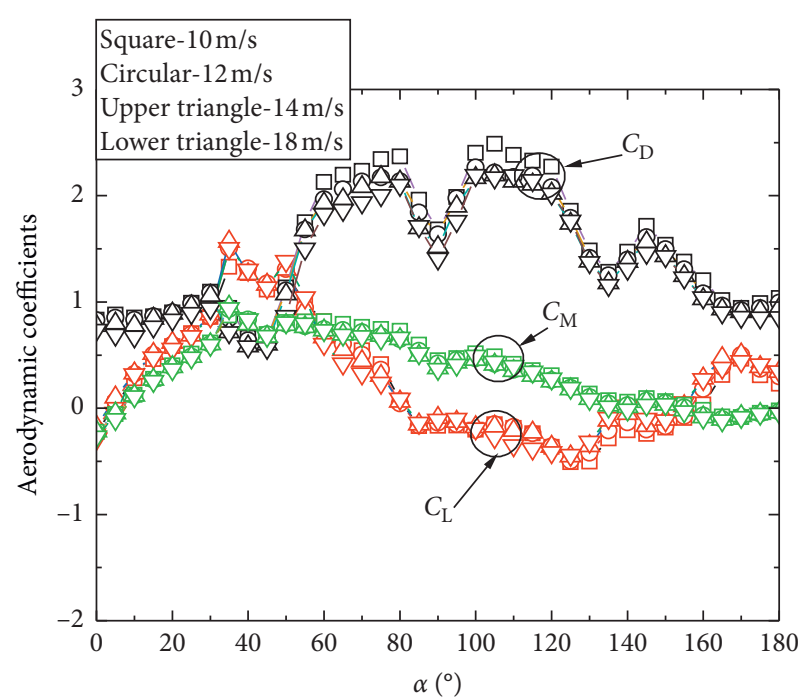

(d)

Figure 6: Aerodynamic coefficients under various wind velocities. (a) Aerodynamic coefficients of subconductor 1. (b) Aerodynamic coefficients of conductor 2. (c) Aerodynamic coefficients of subconductor 3. (d) Aerodynamic coefficients of subconductor 4.

$$
\begin{gathered}
C_{\mathrm{D}}=\frac{F_{\mathrm{D}}}{0.5 \rho U^{2} L D}, \\
C_{\mathrm{L}}=\frac{F_{\mathrm{L}}}{0.5 \rho U^{2} L D}, \\
C_{\mathrm{M}}=\frac{M_{\mathrm{L}}}{0.5 \rho U^{2} L D^{2}},
\end{gathered}
$$

where $L$ is the effective length of the conductor, $F_{\mathrm{D}}$ is the lift load of the conductor, $F_{\mathrm{L}}$ is the drag load, and $M_{\mathrm{L}}$ is the torque of the conductor, respectively.

According to the wind tunnel test, the aerodynamic coefficients of crescent iced quad bundle conductor with $12 \mathrm{~mm}$ iced thickness under the wind speed of $10 \mathrm{~m} / \mathrm{s}, 12 \mathrm{~m} /$ $\mathrm{s}, 14 \mathrm{~m} / \mathrm{s}$, and $18 \mathrm{~m} / \mathrm{s}$ are shown in Figure 6.

Form Figure 6, when $\alpha$ is less than $40^{\circ}$, the curves of the aerodynamic lift coefficients show an upward trend. When $\alpha$ is in the range of $40^{\circ} \sim 120^{\circ}$, the curves of the aerodynamic lift coefficients show a downward trend. When $\alpha$ is in the range of $120^{\circ} \sim 160^{\circ}$, the curves of the aerodynamic lift coefficients have another downing range, but its downward trend is more obvious than that of $\alpha$ being in the range of $40^{\circ} \sim 120^{\circ}$. When $\alpha$ is in the range of $160^{\circ} \sim 180^{\circ}$, the curves of aerodynamic lift coefficients show an upward trend again.

The aerodynamic drag coefficients of subconductor 1 are affected by the wake of subconductor 2 when $\alpha$ is $135^{\circ}$. The aerodynamic drag coefficients of subconductor 3 drop suddenly influenced by the wake of subconductor 2 when $\alpha$ is near $45^{\circ}$. The aerodynamic drag coefficients of subconductor 4 are affected by the wake effect of subconductor 1 , subconductor 2 , and subconductor 3 when $\alpha$ is about $45^{\circ}$, $90^{\circ}$, and $135^{\circ}$, respectively.

When $\alpha$ is less than $45^{\circ}$, the curves of the aerodynamic torque coefficients increase with $\alpha$. When $\alpha$ is greater than $45^{\circ}$, the curves of the aerodynamic torque coefficients decrease with $\alpha$.

Because the subconductor of the iced quad bundle would be effect by wake effects, it is not reasonable to choose the aerodynamic coefficients of one subconductor to study the galloping characteristics of the iced quad bundle conductor. In practical civil engineering, the galloping of the quad bundle conductor usually is expressed as the whole vibration of the quad bundle conductor, so the aerodynamic coefficients at the central axis of the quad bundle conductor are obtained by choosing a reasonable method in this paper.

In order to obtain the three-component aerodynamic coefficients at the central axis of the quad bundle, the equivalent aerodynamic lift coefficients and drag coefficients at the central axis of the quad bundle are defined as follows:

$$
\begin{aligned}
& C_{\mathrm{L}}^{N}=\frac{1}{N} \sum_{i=1}^{N} C_{\mathrm{L}}^{i}, \\
& C_{\mathrm{D}}^{N}=\frac{1}{N} \sum_{i=1}^{N} C_{\mathrm{D}}^{i},
\end{aligned}
$$

where $C_{\mathrm{L}}^{i}$ and $C_{\mathrm{D}}^{i}$, respectively, represent the aerodynamic lift coefficients and aerodynamic drag coefficients of each subconductor of the quad bundle conductor and $N$ represents the number of each subconductor.

The equivalent aerodynamic moment coefficients at the central axis of the quad bundle are defined as follows:

$$
C_{M}^{N}=\frac{1}{N}\left[C_{M, \mathrm{~S}}^{N}+C_{M, \mathrm{D}}^{N}+C_{M, \mathrm{~L}}^{N}\right]
$$

where the physical meaning of $C_{M, S}^{N}, C_{M, \mathrm{D}}^{N}$, and $C_{M, \mathrm{~L}}^{N}$ is the contribution of the torque, drag, and lift of the subconductor to the quad bundle conductor.

According to equations (19a)-(19c), it can be obtained that three-component aerodynamic coefficients at the central axis of the quad bundle under the wind speed of $18 \mathrm{~m} / \mathrm{s}$ are shown in Figure 7. 


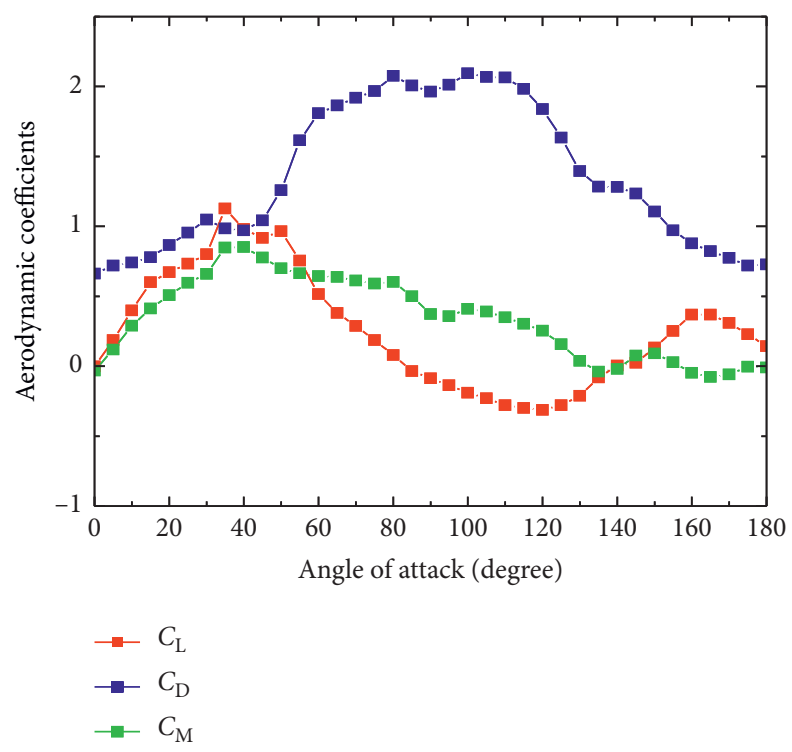

Figure 7: Aerodynamic coefficients at the central axis of the quad bundle.

It can be seen from Figure 7 that the curve of the equivalent aerodynamic lift coefficient of the quad bundle has a negative slope when $\alpha$ is in the ranges of $40^{\circ}-120^{\circ}$ and $160^{\circ}-180^{\circ}$ and it would be easy to gallop. Selecting the threecomponent aerodynamic coefficients when $\alpha$ is $55^{\circ}$, then according to Taylor' rules, it can be obtained that

$$
\begin{gathered}
C_{y}(\alpha)=\left(C_{y} \mid \alpha=0\right)+\left(\frac{\partial C_{y}}{\partial \alpha} \mid \alpha=0\right) \alpha+\left(\frac{\partial^{2} C_{y}}{\partial \alpha^{2}} \mid \alpha=0\right) \alpha^{2}+\left(\frac{\partial^{3} C_{y}}{\partial \alpha^{3}} \mid \alpha=0\right) \alpha^{3}+\mathrm{O}\left(\alpha^{4}\right) \\
C_{z}(\alpha)=\left(C_{z} \mid \alpha=0\right)+\left(\frac{\partial C_{z}}{\partial \alpha} \mid \alpha=0\right) \alpha+\left(\frac{\partial^{2} C_{z}}{\partial \alpha^{2}} \mid \alpha=0\right) \alpha^{2}+\left(\frac{\partial^{3} C_{z}}{\partial \alpha^{3}} \mid \alpha=0\right) \alpha^{3}+\mathrm{O}\left(\alpha^{4}\right), \\
C_{M}(\alpha)=\left(C_{M} \mid \alpha=0\right)+\left(\frac{\partial C_{M}}{\partial \alpha} \mid \alpha=0\right) \alpha+\left(\frac{\partial^{2} C_{M}}{\partial \alpha^{2}} \mid \alpha=0\right) \alpha^{2}+\left(\frac{\partial^{3} C_{M}}{\partial \alpha^{3}} \mid \alpha=0\right) \alpha^{3}+\mathrm{O}\left(\alpha^{4}\right)
\end{gathered}
$$

where the right items of equation (20a) can be expressed as

$$
\begin{gathered}
\left(C_{y} \mid \alpha=0\right)=C_{\mathrm{L}} \cos (\alpha)+C_{\mathrm{D}} \sin (\alpha)=\left(C_{\mathrm{L}} \mid \alpha=0\right) \\
\left(\frac{\partial C_{y}}{\partial \alpha} \mid \alpha=0\right)=\left(\left(\frac{\partial C_{\mathrm{L}}}{\partial \alpha} \cos \alpha-C_{\mathrm{L}} \sin \alpha+\frac{\partial C_{\mathrm{D}}}{\partial \alpha} \sin \alpha+C_{\mathrm{D}} \cos \alpha\right) \mid \alpha=0\right)=\frac{\partial C_{\mathrm{L}}}{\partial \alpha}+C_{\mathrm{D}} \\
\left(\frac{\partial^{2} C_{y}}{\partial \alpha^{2}} \mid \alpha=0\right)=\left(\left(\frac{\partial^{2} C_{\mathrm{L}}}{\partial \alpha^{2}} \cos \alpha-2 \frac{\partial C_{\mathrm{L}}}{\partial \alpha} \sin \alpha-C_{\mathrm{L}} \cos \alpha+\frac{\partial^{2} C_{\mathrm{D}}}{\partial \alpha^{2}} \cos \alpha+2 \frac{\partial C_{\mathrm{D}}}{\partial \alpha} \cos \alpha-C_{\mathrm{D}} \sin \alpha\right) \mid \alpha=0\right)=\frac{\partial^{2} C_{\mathrm{L}}}{\partial \alpha^{2}}-C_{\mathrm{L}}+2 \frac{\partial C_{\mathrm{D}}}{\partial \alpha}, \\
\left(\frac{\partial^{3} C_{y}}{\partial \alpha^{3}} \mid \alpha=0\right)=\left(\left(\frac{\partial^{3} C_{\mathrm{L}}}{\partial \alpha^{3}} \cos \alpha-3 \frac{\partial^{2} C_{\mathrm{L}}}{\partial \alpha^{2}} \sin \alpha-3 \frac{\partial C_{\mathrm{L}}}{\partial \alpha} \cos \alpha+C_{\mathrm{L}} \sin \alpha+\frac{\partial^{3} C_{\mathrm{D}}}{\partial \alpha^{3}} \sin \alpha+3 \frac{\partial^{2} C_{\mathrm{D}}}{\partial \alpha^{2}} \cos \alpha-3 \frac{\partial C_{\mathrm{D}}}{\partial \alpha} \sin \alpha-C_{\mathrm{D}} \cos \alpha\right) \mid \alpha=0\right) \\
=\frac{\partial^{3} C_{\mathrm{L}}}{\partial \alpha^{3}}-3 \frac{\partial C_{\mathrm{L}}}{\partial \alpha}+3 \frac{\partial^{2} C_{\mathrm{D}}}{\partial \alpha^{2}}-C_{\mathrm{D}} .
\end{gathered}
$$


For the constant term in equations (21a)-(21d) is a fixed value, which would not affect the galloping characteristics of the iced quad bundle conductor, then by ignoring the constant term and substituting equations (21a)-(21d) into equation (20a), it can be obtained that

$$
C_{y}=\left(\frac{\partial C_{L}}{\partial \alpha}+C_{D}\right) \alpha+\left(\frac{\partial^{2} C_{L}}{\partial \alpha^{2}}-C_{L}+2 \frac{\partial C_{D}}{\partial \alpha}\right) \alpha^{2}+\left(\frac{\partial^{3} C_{L}}{\partial \alpha^{3}}-3 \frac{\partial C_{L}}{\partial \alpha}+3 \frac{\partial^{2} C_{D}}{\partial \alpha^{2}}-C_{D}\right) \alpha^{3}+\mathrm{O}\left(\alpha^{4}\right)
$$

In the same way, the aerodynamic coefficients in the transverse and torsional direction can be expressed as

$$
\begin{aligned}
C_{z} & =\left(\frac{\partial C_{\mathrm{D}}}{\partial \alpha}+C_{\mathrm{L}}\right) \alpha+\left(\frac{\partial^{2} C_{\mathrm{D}}}{\partial \alpha^{2}}-C_{\mathrm{D}}-2 \frac{\partial C_{\mathrm{L}}}{\partial \alpha}\right) \alpha^{2}+\left(\frac{\partial^{3} C_{\mathrm{D}}}{\partial \alpha^{3}}-3 \frac{\partial C_{\mathrm{D}}}{\partial \alpha}-3 \frac{\partial^{2} C_{\mathrm{L}}}{\partial \alpha^{2}}+C_{\mathrm{L}}\right) \alpha^{3}+\mathrm{O}\left(\alpha^{4}\right) \\
C_{z}(\alpha) & =\frac{\partial C_{\mathrm{M}}}{\partial \alpha} \alpha+\frac{\partial^{2} C_{M}}{\partial \alpha^{2}} \alpha^{2}+\frac{\partial^{3} C_{\mathrm{M}}}{\partial \alpha^{3}} \alpha^{3}+\mathrm{O}\left(\alpha^{4}\right)
\end{aligned}
$$

Let the coefficients of the primary term, the coefficient of the secondary term, and the coefficient of the tertiary term of $\alpha$ in equation (22a) be $\alpha_{1}, \alpha_{2}$, and $\alpha_{3}$, respectively; that is,

$$
\begin{array}{r}
\frac{\partial C_{\mathrm{L}}}{\partial \alpha}+C_{\mathrm{D}}=\alpha_{1}, \\
\frac{\partial^{2} C_{\mathrm{L}}}{\partial \alpha^{2}}-C_{\mathrm{L}}+2 \frac{\partial C_{\mathrm{D}}}{\partial \alpha}=\alpha_{2} \\
\frac{\partial^{3} C_{\mathrm{L}}}{\partial \alpha^{3}}-3 \frac{\partial C_{\mathrm{L}}}{\partial \alpha}+3 \frac{\partial^{2} C_{\mathrm{D}}}{\partial \alpha^{2}}-C_{\mathrm{D}}=\alpha_{3} .
\end{array}
$$

Then, $C_{y}(\alpha)$ can be expressed as

$$
C_{y}=\alpha_{1} \alpha+\alpha_{2} \alpha^{2}+\alpha_{3} \alpha^{3}
$$

In the same way, $C_{Z}(\alpha)$ and $C_{M}(\alpha)$ can be expressed as

$$
\begin{aligned}
& C_{z}=\beta_{1} \alpha+\beta_{2} \alpha^{2}+\beta_{3} \alpha^{3}, \\
& C_{M}=\gamma_{1} \alpha+\gamma_{2} \alpha^{2}+\gamma_{3} \alpha^{3} .
\end{aligned}
$$

Finally, it can be obtained that

$$
\begin{gathered}
C_{y}=-0.96060 \alpha-1.40716 \alpha^{2}+97.62315 \alpha^{3}, \\
C_{z}=2.39795 \alpha-7.00826 \alpha^{2}-119.95612 \alpha^{3}, \\
C_{M}=2.6744 \alpha+22.30868 \alpha^{2}-132.0081 \alpha^{3}
\end{gathered}
$$

\section{Numerical Analysis}

The galloping characteristics of the iced quad bundle conductor are investigated and the galloping characteristics of the iced quad bundle conductor obtained by these two discrete methods will be compared in this paper. Since the physical parameters of the iced quad bundle conductor are involved, the parameters of the quad bundle conductor are listed in Table 1 [20].

By substituting the physical parameters into equations (16) and (17) and combining the three-component aerodynamic coefficients in equation (25), the displacement response of the iced quad bundle conductor under direct discrete method and indirect discrete method can be obtained by using the Runge-Kutta method, as shown in Figures 8 and 9 .

From Figures 8 and 9, it can be seen that the iced quad bundle conductor gradually tends to be stable at $400 \mathrm{~s}$ under these two discrete methods; that is, the differences in the discrete method would not change the time when the iced quad bundle conductor reaches the steady state. It also can be found that the amplitudes obtained by these two discrete methods are different to some extent, and the most obvious differences are amplitude in the torsional direction.

In order to compare the differences of the displacement response obtained by these two discrete methods more clearly, selecting the data as the iced quad bundle conductor is in the steady state to obtain the local curves of displacement response, which are shown in Figure 10. 
TABle 1: Physical parameters of the conductor.

\begin{tabular}{lccc}
\hline Parameters & Notation & Units & For line \\
\hline Axial rigidity & $\mathrm{AE}$ & $10^{6} \mathrm{~N}$ & 13.30 \\
Torsional rigidity & $\mathrm{GI}_{P}$ & $\mathrm{Nm}^{2} \mathrm{rad}^{-1}$ & 101 \\
Diameter & $D$ & $10^{-3} \mathrm{~m}$ & 18.80 \\
Tension & $H$ & $10^{3} \mathrm{~N}$ & 21.73 \\
Damping $(y)$ & $\zeta_{y}$ & $10^{-2}$ & 0.067 \\
Damping $(z)$ & $\zeta_{z}$ & $10^{-3}$ & 0.067 \\
Damping $(\theta)$ & $\zeta_{\theta}$ & $10^{-2}$ & 0.253 \\
Mass per unit length & $M$ & $\mathrm{~kg} \mathrm{~m}^{-1}$ & 1.53 \\
The moment of inertia & $J$ & $10^{-4} \mathrm{~kg} \mathrm{~m}^{-1}$ & 57.02 \\
The static moment & $S y$ & $\mathrm{~kg} \mathrm{~m} \mathrm{~m}^{-1}$ & 0.000459 \\
The static moment & $S_{Z}$ & $\mathrm{~kg} \mathrm{~m} \mathrm{~m}^{-1}$ & -0.000145 \\
\hline
\end{tabular}

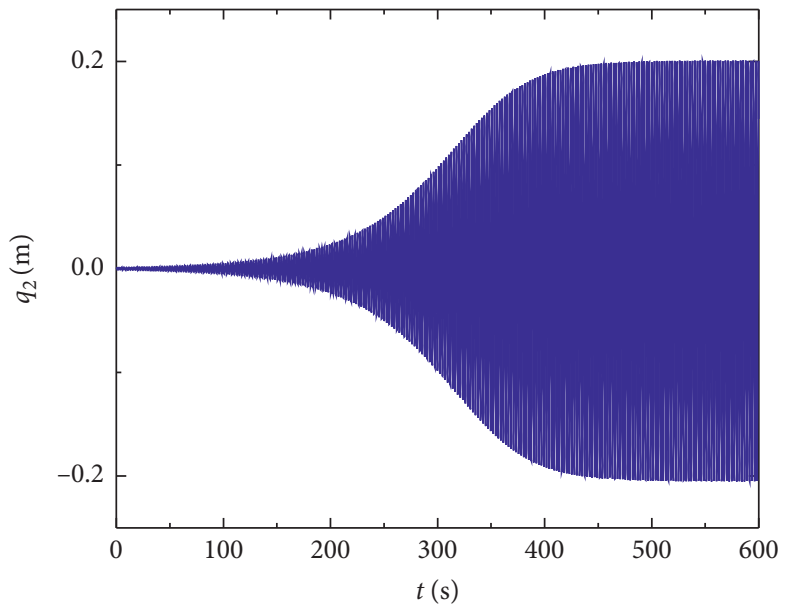

(a)

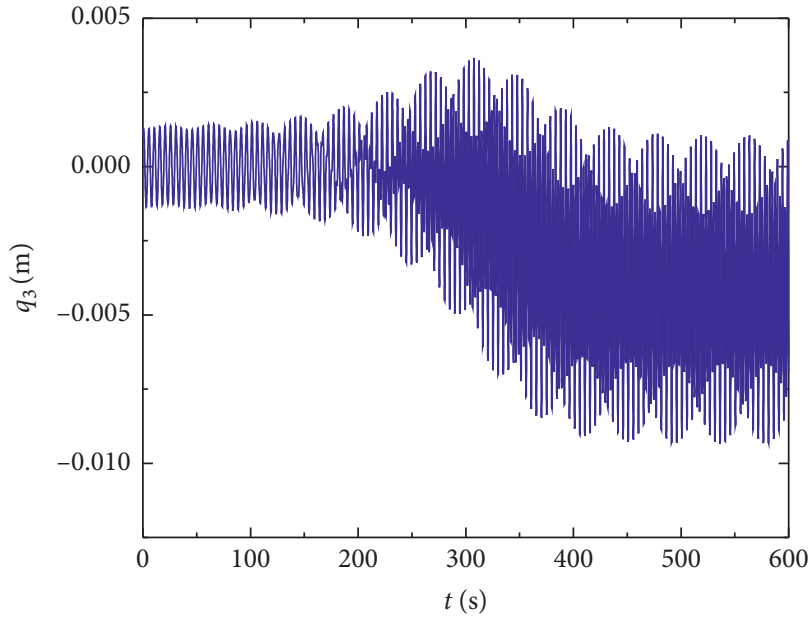

(b)

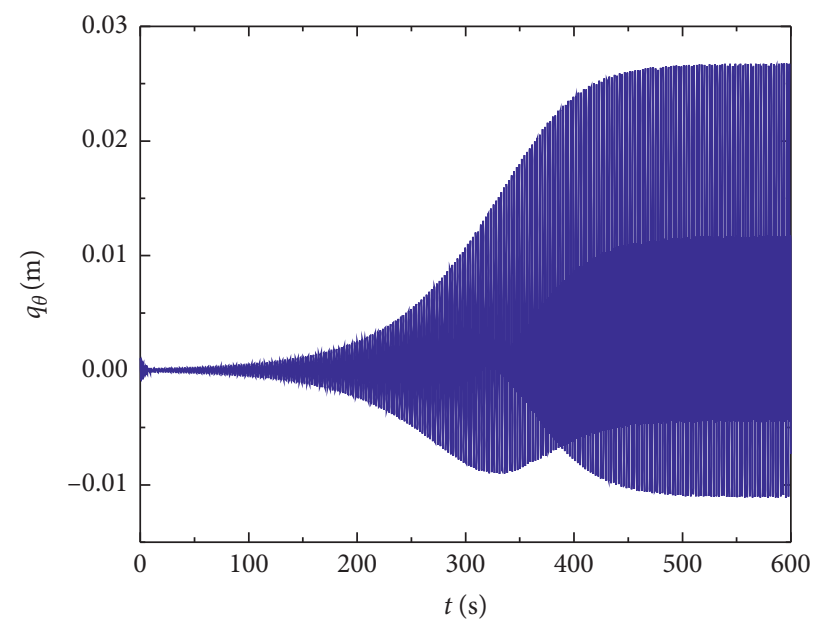

(c)

Figure 8: Displacement response under direct discrete method. (a) Vertical displacement. (b) Transverse displacement. (c) Torsional displacement. 


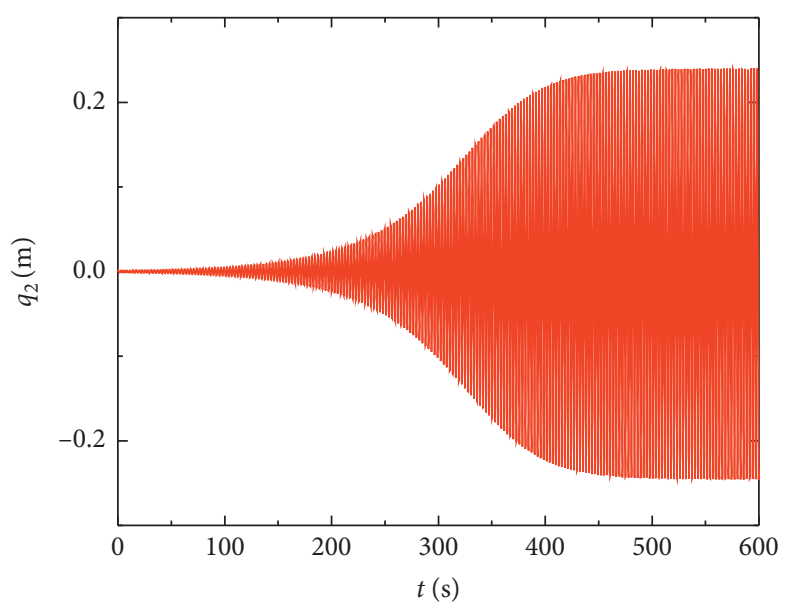

(a)

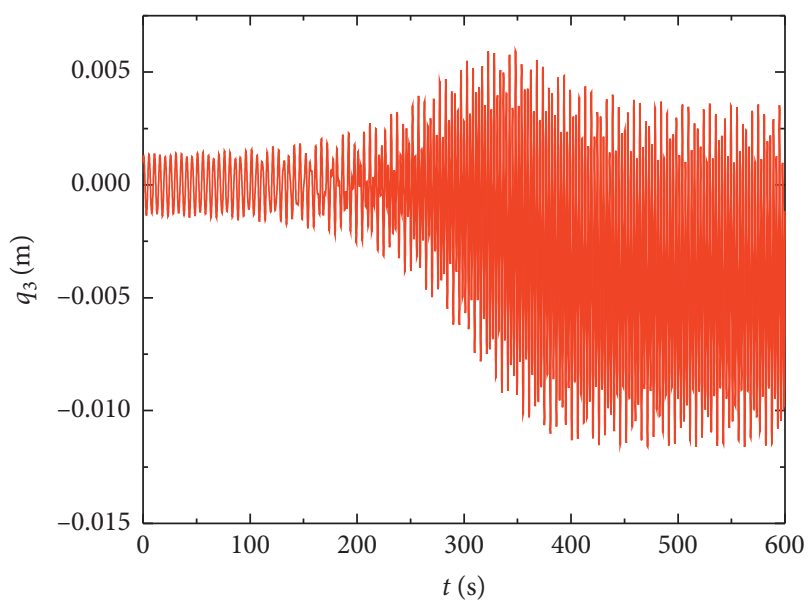

(b)

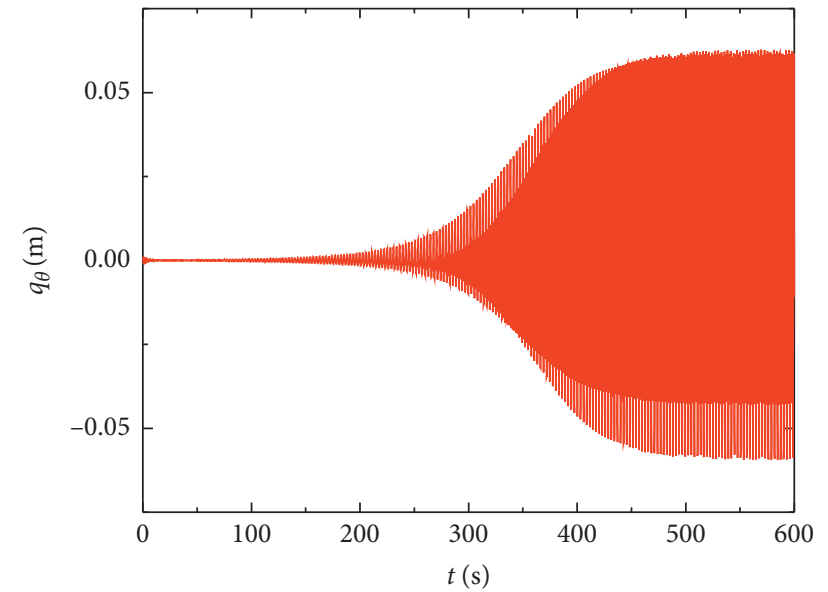

(c)

FIgURE 9: Displacement response under indirect discrete method. (a) Vertical displacement. (b) Transverse displacement. (c) Torsional displacement.

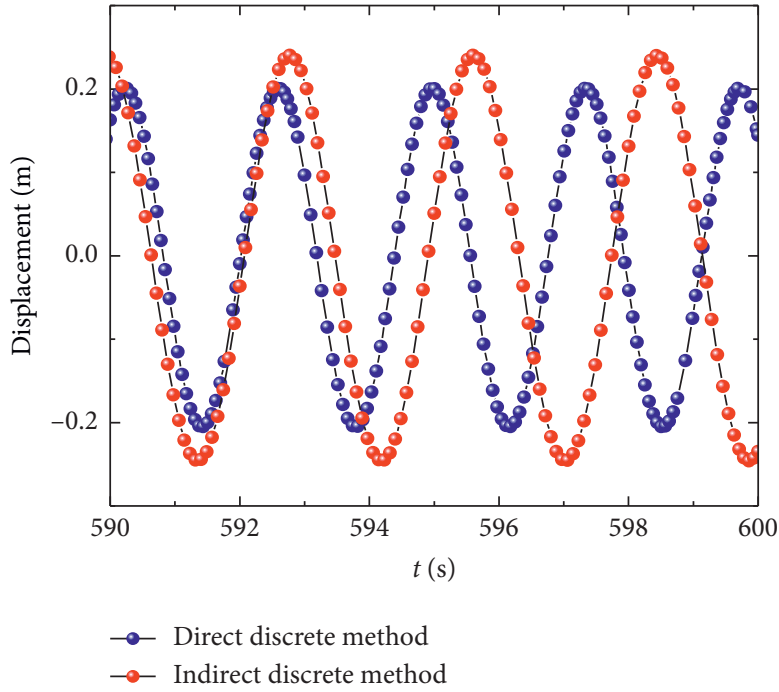

(a)

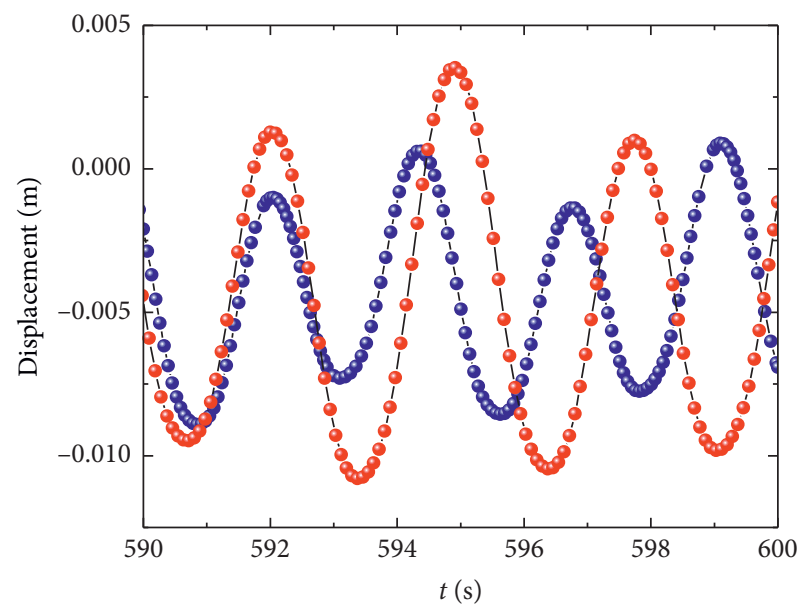

-o- Direct discrete method

$\rightarrow$ Indirect discrete method

(b)

FIgURE 10: Continued. 


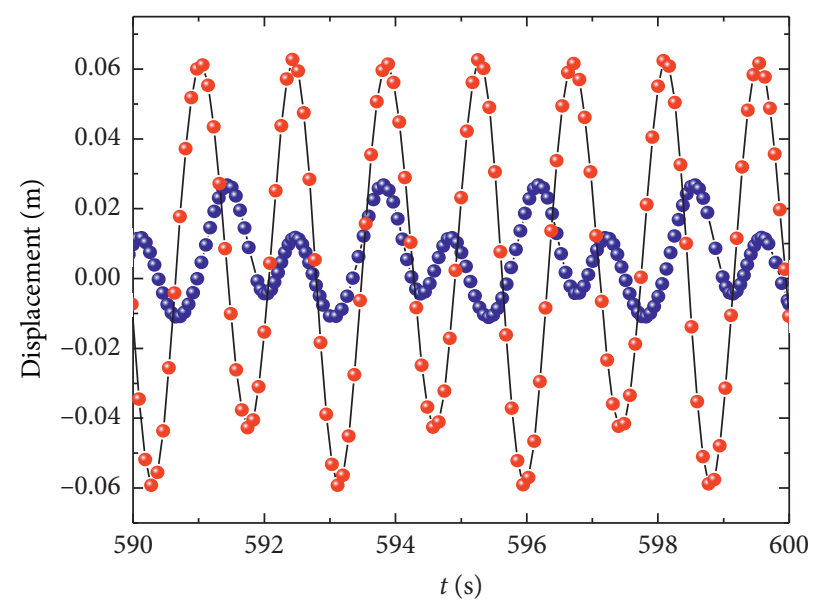

- Direct discrete method

$\rightarrow$ Indirect discrete method

(c)

Figure 10: Local displacement. (a) Vertical displacement, (b) Transverse displacement, (c) Torsional displacement.

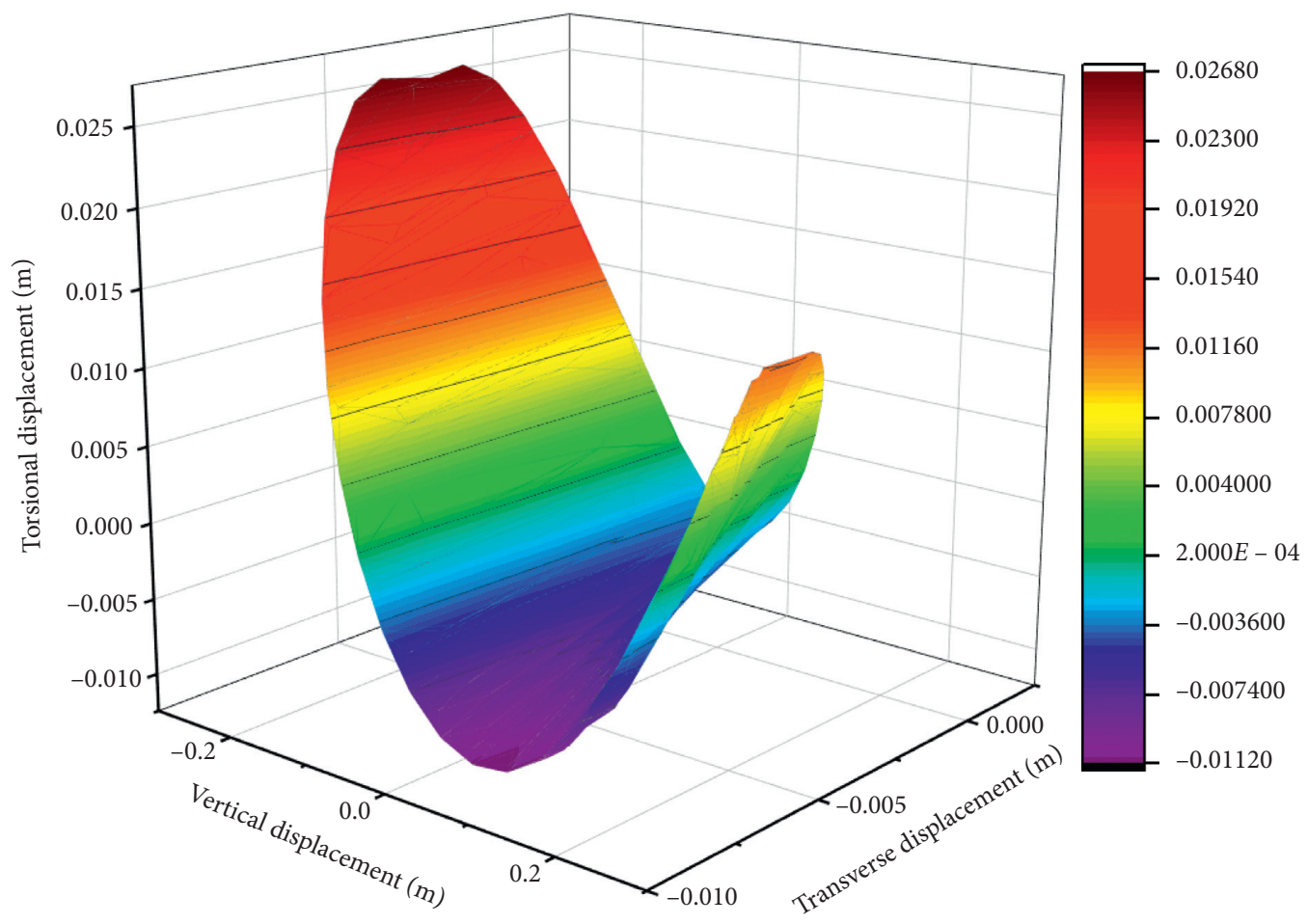

(a)

FIgure 11: Continued. 


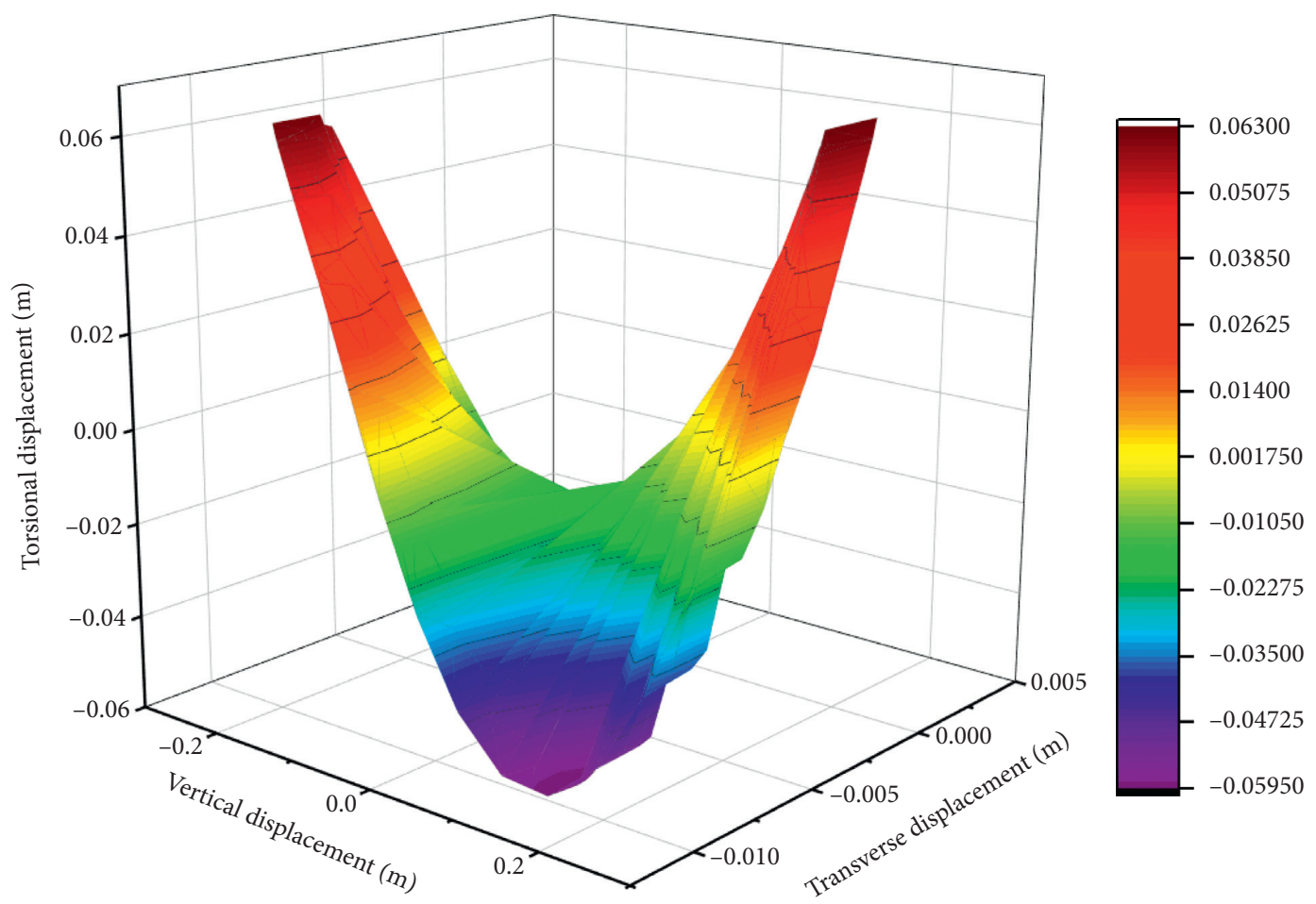

(b)

Figure 11: Amplitude diagrams. (a) Direct discrete method. (b) Indirect discrete method.

It can be seen from Figure 10 that, in the transverse and torsional directions, the amplitude of the indirect discrete method is greater than that of the direct discrete method, and the differences of the amplitude in the torsional direction are particularly obvious. The frequency, phase, and amplitude of the iced quad bundle conductor obtained by the two discrete methods are different to some extent. Different discrete methods may lead to some errors between the theoretical results and the actual conditions, which is a noteworthy phenomenon.

When the iced quad bundle conductor is galloping, the amplitude is one of the most concerned parameters for the studying of galloping characteristics. Because the amplitude in the torsion direction obtained by the two discrete methods has obvious differences, in order to compare the amplitude in the torsion direction obtained by the two discrete methods more clearly, amplitude diagrams below are obtained which are shown in Figure 11.

Form Figure 11, the maximum amplitude in the torsion direction obtained by the direct discrete method is $0.02680 \mathrm{~m}$, while the maximum amplitude in the torsion direction obtained by the indirect discrete method is $0.06300 \mathrm{~m}$. This is because the indirect discrete method ignores the axial inertial force of the iced quad bundle conductor, which leads to the increase of the amplitude in the torsional direction compared with the amplitude in the torsional direction obtained by the direct discrete method.

\section{Conclusions}

Firstly, based on the variational principle for Hamiltonian, the partial differential galloping equation with $3 \mathrm{DOF}$ of the iced quad bundle conductor is derived; then two discrete methods are used to transform the partial differential galloping equation into an ordinary differential galloping equation. Secondly, based on the wind tunnel test, the three-component aerodynamic coefficients of each subconductor of the iced quad conductor are obtained; then, the equivalent aerodynamic coefficients at the central axis of the quad bundle conductor are obtained by using a reasonable method. Finally, based on the numerical method, the displacement responses of the two discrete methods are obtained. The following conclusions can be listed:

(1) Based on the wind tunnel test, it can obtain that each subconductor of the iced quad bundle conductor would be effect by wake effects, so it is not reasonable to choose the aerodynamic coefficients of one subconductor to investigation on the galloping characteristics of the iced quad bundle conductor. For studying the galloping characteristics of the iced quad bundle conductor, three-component aerodynamic coefficients at the central axis of the quad bundle should be obtained firstly. 
(2) Based on the numerical method, it can be obtained that the amplitude of the indirect discrete method is greater than that of the direct discrete method, and the differences of the amplitude in the torsional direction are particularly obvious. The frequency and phase of the galloping of the iced quad bundle conductor obtained by the two discrete methods are also different to some extent. This is because the indirect discrete method ignores the axial inertial force of the iced quad bundle conductor, which leads to the increase of the amplitude in the torsional direction compared with the amplitude in the torsional direction obtained by the direct discrete method.

(3) Based on the fact that the calculation process of the partial differential galloping equation is transformed into an ordinary differential galloping equation, it can be obtained that the calculation process of the direct discrete method is more complex and the calculation process of the indirect discrete method is simpler. However, based on the calculation results of the galloping characteristics, the amplitude obtained by the indirect discrete method is bigger than that obtained by the direct discrete method, especially the amplitude in the torsional direction. This is because the indirect discrete method ignores the axial inertial force of the iced quad bundle conductor since the amplitude in the torsional direction obtained by it is worthy of further discussion.

\section{Appendix}

$$
\begin{aligned}
& b_{1}=\int_{0}^{l} m \psi_{2}^{2} \mathrm{~d} x \\
& b_{2}=\int_{0}^{l} f_{2} \psi_{2}^{2} \mathrm{~d} x \\
& b_{4}=\int_{0}^{l}\left\{\mathrm{EI} \psi_{2}^{\prime}-\frac{\partial}{\partial x}\left(H \psi_{2}^{\prime}+\mathrm{EA} y^{\prime 2} \psi_{2}^{\prime}\right)\right\} \psi_{2} \mathrm{~d} x \\
& b_{5}=-\int_{0}^{l} \frac{\partial}{\partial x}\left(\frac{3 \mathrm{EA}}{2} y^{\prime} \psi_{2}^{\prime 2}\right) \psi_{2} \mathrm{~d} x \\
& b_{6}=-\int_{0}^{l} \frac{\partial}{\partial x}\left(\frac{\mathrm{EA}}{2} y^{\prime} \psi_{3}^{\prime 2}\right) \psi_{2} \mathrm{~d} x \\
& b_{8}=-\int_{0}^{l} \frac{\partial}{\partial x}\left(\frac{\mathrm{EA}}{2} y^{\prime} \psi_{2}^{\prime 3}\right) \psi_{2} \mathrm{~d} x, \\
& b_{9}=-\int_{0}^{l} \frac{\partial}{\partial x}\left(\frac{\mathrm{EA}}{2} \psi_{2}^{\prime} \psi_{3}^{\prime 2}\right) \psi_{2} \mathrm{~d} x, \\
& b_{10}=-\int_{0}^{l} S_{y} \psi_{\theta} \psi_{2} \mathrm{~d} x
\end{aligned}
$$

$$
\begin{aligned}
p p_{2} & =\int_{0}^{l} p_{2} \psi_{2} \mathrm{~d} x, \\
b_{1}^{\prime} & =\int_{0}^{l} m \psi_{2}^{2} \mathrm{~d} x, \\
b_{2}^{\prime} & =\int_{0}^{l} f_{2} \psi_{2}^{2} \mathrm{~d} x, \\
b_{4}^{\prime} & =\int_{0}^{l}\left(\mathrm{EI} \psi_{2}^{\prime \prime \prime \prime}-\frac{\mathrm{EA}}{l} y^{\prime \prime \prime \prime} \int_{0}^{l} y^{\prime} \psi_{2}^{\prime} d x-H \psi_{2}^{\prime \prime}\right) \psi_{2} \mathrm{~d} x,
\end{aligned}
$$$$
b_{5}^{\prime}=-\int_{0}^{l}\left\{\left(\frac{\mathrm{EA}}{2 l} y^{\prime \prime} \int_{0}^{l} \psi_{2}^{\prime 2} \mathrm{~d} x\right)\right.
$$$$
\left.+\int_{0}^{l}\left(\frac{\mathrm{EA}}{l} \psi_{2}^{\prime \prime \prime \prime} \int_{0}^{l} y^{\prime} \psi_{2}^{\prime} \mathrm{d} x\right)\right\} \psi_{2} \mathrm{~d} x \text {, }
$$$$
b_{6}^{\prime}=-\int_{0}^{l} \frac{\mathrm{EA}}{2 l} y^{\prime \prime} \int_{0}^{l} \psi_{3}^{\prime 2} \mathrm{~d} x \psi_{2} \mathrm{~d} x,
$$$$
b_{10}{ }^{\prime}=-\int_{0}^{l} S_{y} \psi_{\theta} \psi_{2} \mathrm{~d} x \text {, }
$$

$$
\begin{aligned}
& b_{8}^{\prime}=-\int_{0}^{l}\left(\frac{E A}{2 l} \psi_{2}^{\prime \prime} \int_{0}^{l} \psi_{2}^{\prime 2} \mathrm{~d} x\right) \psi_{2} \mathrm{~d} x, \\
& b_{9}^{\prime}=-\int_{0}^{l}\left(\frac{E A}{2 l} \psi_{2}^{\prime \prime} \int_{0}^{l} \psi_{3}^{\prime 2} \mathrm{~d} x\right) \psi_{2} \mathrm{~d} x,
\end{aligned}
$$$$
p p_{2}^{\prime}=\int_{0}^{l} f_{2} \psi_{2}^{2} \mathrm{~d} x \text {, }
$$$$
c_{1}=\int_{0}^{l} m \psi_{3}^{2} \mathrm{~d} x,
$$$$
c_{2}=\int_{0}^{l} f_{3} \psi_{3}^{2} \mathrm{~d} x \text {, }
$$$$
c_{3}=\int_{0}^{l}\left[\mathrm{EI} \psi_{3}^{\prime \prime \prime \prime}-\frac{\partial}{\partial x}\left(H \psi_{3}^{\prime}\right)\right] \psi_{3} \mathrm{~d} x,
$$$$
c_{5}=-\int_{0}^{l} \frac{\partial}{\partial x}\left(\mathrm{EA} \psi_{3}^{\prime} \psi_{2}^{\prime} y^{\prime}\right) \psi_{3} \mathrm{~d} x \text {, }
$$$$
c_{6}=-\int_{0}^{l} \frac{\partial}{\partial x}\left(\frac{\mathrm{EA}}{2} \psi \psi_{3}^{\prime} \psi_{2}^{\prime 2}\right) \psi_{3} \mathrm{~d} x \text {, }
$$$$
c_{7}=-\int_{0}^{l} \frac{\partial}{\partial x}\left(\frac{\mathrm{EA}}{2} \psi^{\prime 3}{ }_{3}^{3}\right) \psi_{3} \mathrm{~d} x,
$$$$
c_{8}=\int_{0}^{l} S_{z} \psi_{\theta} \psi_{3} \mathrm{~d} x \text {, }
$$$$
p p_{3}=\int_{0}^{l} p_{3} \psi_{3} \mathrm{~d} x \text {, }
$$$$
c_{1}^{\prime}=\int_{0}^{l} m \psi_{3}^{2} \mathrm{~d} x,
$$$$
c_{2}^{\prime}=\int_{0}^{l} f_{3} \psi_{3}^{2} \mathrm{~d} x,
$$

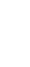




$$
\begin{aligned}
c_{3}^{\prime} & =\int_{0}^{l}\left(\mathrm{EI}_{3}^{\prime \prime \prime \prime}-H \psi_{3}^{\prime \prime}\right) \psi_{3} \mathrm{~d} x, \\
c_{5}^{\prime} & =-\int_{0}^{l}\left(\frac{\mathrm{EA}}{l} \psi_{3}^{\prime \prime} \int_{0}^{l} y^{\prime} \psi_{2}^{\prime} \mathrm{d} x\right) \psi_{3} \mathrm{~d} x, \\
c_{6}^{\prime} & =-\int_{0}^{l}\left(\frac{\mathrm{EA}}{l} \psi_{3}^{\prime \prime} \int_{0}^{l} \psi_{2}^{\prime 2} \mathrm{~d} x\right) \psi_{3} \mathrm{~d} x, \\
c_{7}^{\prime} & =-\int_{0}^{l}\left(\frac{\mathrm{EA}}{2 l} \psi_{3}^{\prime \prime} \int_{0}^{l} \psi_{3}^{\prime 2} \mathrm{~d} x\right) \psi_{3} \mathrm{~d} x, \\
c_{8}^{\prime} & =\int_{0}^{l} S_{z} \psi_{\theta} \psi_{3} \mathrm{~d} x, \\
p p_{3}^{\prime} & =\int_{0}^{l} p_{3} \psi_{3} \mathrm{~d} x, \\
d_{1} & =\int_{0}^{l} J \psi_{\theta}^{2} \mathrm{~d} x, \\
d_{2} & =\int_{0}^{l} f_{\theta} \psi_{\theta}^{2} \mathrm{~d} x,
\end{aligned}
$$

$$
\begin{aligned}
d_{3} & =\int_{0}^{l} S_{z} \psi_{3} \psi_{\theta} \mathrm{d} x, \\
d_{4} & =-\int_{0}^{l} S_{y} \psi_{2} \psi_{\theta} \mathrm{d} x, \\
d_{5} & =-\int_{0}^{l} G I_{p} \psi_{\theta}^{\prime \prime} \psi_{\theta} \mathrm{d} x, \\
p p_{4} & =\int_{0}^{l} p_{\theta} \psi_{\theta} \mathrm{d} x, \\
d_{1}^{\prime} & =\int_{0}^{l} J \psi_{\theta}^{2} \mathrm{~d} x,
\end{aligned}
$$$$
d_{2}^{\prime}=\int_{0}^{l} f_{\theta} \psi_{\theta}^{2} \mathrm{~d} x
$$$$
d_{3}^{\prime}=\int_{0}^{l} S_{z} \psi_{3} \psi_{\theta} \mathrm{d} x
$$$$
d_{4}^{\prime}=-\int S_{y} \psi_{2} \psi_{\theta} \mathrm{d} x
$$$$
d_{5}^{\prime}=-\int_{0}^{l} \mathrm{GI}_{p} \psi_{\theta}^{\prime \prime} \psi_{\theta} \mathrm{d} x
$$$$
p p_{4}^{\prime}=\int_{0}^{l} p_{\theta} \psi_{\theta} \mathrm{d} x
$$$$
b^{*}=\int_{0}^{l}-\frac{1}{2} \rho U^{2} D\left(-\frac{\alpha_{1}}{U}\right) \psi_{2}(x)^{2} \mathrm{~d} x,
$$$$
b_{11}^{*}=\int_{0}^{l}-\frac{1}{2} \rho U^{2} D\left(\frac{\alpha_{2}}{U^{2}}\right) \psi_{2}(x)^{3} \mathrm{~d} x \text {, }
$$$$
b_{12}^{*}=\int_{0}^{l}-\frac{1}{2} \rho U^{2} D\left(-\frac{\alpha_{3}}{U^{3}}\right) \psi_{2}(x)^{4} \mathrm{~d} x \text {, }
$$

$$
\begin{aligned}
& c_{9}^{*}=\int_{0}^{l}-\frac{1}{2} \rho U^{2} D\left(-\frac{\beta_{1}}{U}\right) \psi_{2}(x) \psi_{3}(x) \mathrm{d} x, \\
& c_{10}^{*}=\int_{0}^{l}-\frac{1}{2} \rho U^{2} D\left(\frac{\beta_{2}}{U^{2}}\right)\left[\psi_{2}(x)\right]^{2} \psi_{3}(x) \mathrm{d} x, \\
& c_{11}^{*}=\int_{0}^{l}-\frac{1}{2} \rho U^{2} D\left(-\frac{\beta_{3}}{U^{3}}\right)\left[\psi_{2}(x)\right]^{3} \psi_{3}(x) \mathrm{d} x, \\
& d_{6}^{*}=\int_{0}^{l}-\frac{1}{2} \rho U^{2} D^{2}\left(-\frac{\gamma_{1}}{U}\right) \psi_{2}(x) \psi_{\theta}(x) \mathrm{d} x, \\
& d_{7}^{*}=\int_{0}^{l}-\frac{1}{2} \rho U^{2} D^{2}\left(\frac{\gamma_{2}}{U^{2}}\right)\left[\psi_{2}(x)\right]^{2} \psi_{\theta}(x) \mathrm{d} x, \\
& d_{8}^{*}=\int_{0}^{l}-\frac{1}{2} \rho U^{2} D^{2}\left(-\frac{\gamma_{3}}{U^{3}}\right)\left[\psi_{2}(x)\right]^{3} \psi_{\theta}(x) \mathrm{d} x .
\end{aligned}
$$

\section{Data Availability}

The data used to support this study are available from the corresponding author upon request.

\section{Conflicts of Interest}

The authors declare that there are no conflicts of interest regarding the publication of this paper.

\section{Acknowledgments}

This work was financially supported by the National Natural Science Foundation of China (51507106 and 51308570), Cutting Edge Project of Chongqing Science and Technology Commission (cstc2017jcyjAX0246), Graduate Research and Innovation Project of Chongqing (cys19240), China Postdoctoral Science Foundation (2020M672238), Chengdu International Science and Technology Cooperation Support Funding (2020GH02-00059-HZ), and Technology Research Project of Chongqing Education Commission (KJ201600712182).

\section{References}

[1] X. Li, D. Yu, and Z. Li, "Parameter analysis on wind-induced vibration of UHV cross-rope suspension tower-line," $A d$ vances in Civil Engineering, vol. 2017, Article ID 8756019, 9 pages, 2017.

[2] X. H. Liu, Y. Hu, and M. Q. Cai, "Free vibration analysis of transmission lines based on the dynamic stiffness method," Royal Society Open Science, vol. 6, no. 3, Article ID 181354, 2019.

[3] X. Liu, L. Liu, M. Cai, and B. Yan, "Free vibration of transmission lines with multiple insulator strings using refined models," Applied Mathematical Modelling, vol. 67, pp. 252-282, 2019.

[4] M. Cai, L. Zhou, H. Lei, and H. Huang, "Wind tunnel test investigation on unsteady aerodynamic coefficients of iced 4bundle conductors," Advances in Civil Engineering, vol. 2019, Article ID 2586242, 12 pages, 2019. 
[5] J. Li, M. Zhang, and G. Zhao, "Nonlinear dynamic analysis of high-voltage overhead transmission lines," Shock and Vibration, vol. 2018, Article ID 1247523, 2018.

[6] H. M. Irvine, Cable Structures, The MIT Press, London, UK, 1981.

[7] N. C. Perkins, "Modal interactions in the non-linear response of elastic cables under parametric/external excitation," International Journal of Non-Linear Mechanics, vol. 27, no. 2, pp. 233-250, 1992.

[8] G. Rega, Theoretical and Experimental Nonlinear Vibrations of Sagged Elastic Cables//Nonlinear Dynamic Phenomena in Mechanics, Springer Netherlands, Dordrecht, Netherlands, 2011.

[9] J. L. Lilien and D. G. Havard, "Galloping data base on single and bundle conductors prediction on maximum amplitudes," IEEE Transactions on Power Delivery, vol. 15, no. 2, pp. 670-674, 2000.

[10] Z. Yan, E. Savory, Z. Li, and W. E. Lin, "Galloping of iced quad-conductors bundles based on curved beam theory," Journal of Sound and Vibration, vol. 333, no. 6, pp. 1657-1670, 2014.

[11] Y. Xiao, W. D. Zhou, and L. C. Fan, "Analytical solution of in-plane free vibration of suspension cables considering bending stiffness," Journal of Earthquake Engineering and Engineering Vibration, vol. 33, no. 4, pp. 75-80, 2013, in Chinese.

[12] Y. Y. Zhao, H. B. Zhou, B. Jin, and W. C. Liu, "Internal response of inclined cable considering bending rigidity," Journal of Hunan University (Natural Sciences), vol. 34, no. 05, pp. 1-5, 2007, in Chinese.

[13] K. M. Kimura, Y. Inoue, T. Fujino et al., "Unsteady forces on an ice-accreted four-conductor bundle transmission line," in Proceedings of the 10th International Conference on Wind Engineering, pp. 467-472, Copenhagen: Denmark, June 1999.

[14] W. J. Lou, J. Lv, M. F. Huang, L. Yang, and D. Yan, "Aerodynamic force characteristics and galloping analysis of iced bundle conductors"” Wind and Structures, vol. 18, no. 2, pp. 135-154, 2014.

[15] M. Cai, Q. Xu, L. Zhou, X. Liu, and H. Huang, "Aerodynamic characteristics of iced 8-bundle conductors under different turbulence intensities," KSCE Journal of Civil Engineering, vol. 23, no. 11, pp. 4812-4823, 2019.

[16] W. J. Lou, L. Yang, M. F. Huang, M. Asce, and X. H. Yang, "Two-parameter bifurcation and stability analysis for nonlinear galloping of iced transmission lines," Journal of Engineering Mechanics, vol. 140, no. 11, Article ID 04014081, 2014.

[17] Y. Y. Zhao, L. H. Wang, D. L. Chen, and L. Z. Jiang, "Threedimensions nonlinearity dynamics analysis of inclined-cable," Journal of Hunan University (Natural Science), vol. 2011, no. 3, pp. 90-96, 2001, in Chinese.

[18] A. Luongo, D. Zulli, and G. Piccardo, "Analytical and numerical approaches to nonlinear galloping of internally-resonant suspended cable," Journal of Sound and Vibration, vol. 315, no. 3, pp. 375-393, 2008.

[19] L. H. Wang and Y. Y. Zhao, "Large amplitude motion mechanism and non-planar vibration character of stay cables subject to the support motions," Journal of Sound and Vibration, vol. 327, no. 1, pp. 121-133, 2009.

[20] Y. M. Desal, P. Yu, N. Popplewell, and A. H. Shah, "Finite element modeling of transmission line galloping"' Computers and Structures, vol. 57, no. 3, pp. 407-420, 1995. 